\title{
Circulating Tumor Cell Separation of Blood Cells and Sorting in novel Microfluidic approaches: a review
}

\author{
A.Farahinia ${ }^{1 *}$, W.J. Zhang², I. Badea ${ }^{3}$
}

\begin{abstract}
Separation and interpretation of rebellious Circulating Tumor Cells (CTCs) originating from the primary tumor or cancer tissue plays a significant role in diagnostics, cancer progression analyses, suitable medicine exploration, and treatment proficiency examination. Cancer metastasis occurs when CTCs spread throughout the body and invade healthy tissues, leading to new tumors in that area. Although a dramatic rate of deaths begins from spreading CTCs around the body, valuable measures have been made to control their development. However, the first step is separating these harmful cells from the bloodstream and investigating their features. Having examined the characteristics of CTCs as cancer's main strength, researchers can introduce complementary treatments that can affect cancerous cells without damaging the healthy cells. Therefore, according to their unique characteristics, numerous techniques have been established for continuous and fast separation and sorting of CTCs. Nevertheless, few separators enjoy the efficient performance and appropriate accuracy and can be produced in mass numbers due to the available fabrication equipment. Microfabrication advancements enable separators to combine the advantages of active and passive methods in a small-scale platform for probing individual cells and separation purposes. Reduction in reagents, sample volume, analysis time, and less harmfulness to patients are some of the motivations that encourage researchers to employ microfluidic instruments for CTCs separation from other blood cells over the last two decades. However, microfabrication limitations mean effective separators, and the diagnostic option they provide, are not readily available. Addressing these limitations requires optimizing the design and fabrication of separators such that they are reduced in their size and fabrication cost, while also maintaining high-throughput separating capability. The emergence of the Lab-On-a-Chip (LOC) and then Lab-On-a-CD (LOCD) technologies, having more inherent benefits than conventional microfluidic devices, has created new opportunities and become increasingly widespread in recent years. Evidence suggests that employing single methodologies or integrating approaches without sufficient understanding of potential outcomes is unlikely to result in successful diagnostic results. This paper contributes an extensive review of several separation systems, including fundamental theories and experimental details, and describes detailed operating principles and device performance.
\end{abstract}

\section{KEYWORDS:}

Cancerous Cell, Tumors, Cancer Metastasis, Circulating Tumor Cells (CTCs), Microfluidic Devices, labOn-a-Chip (LOC), Lab-On-a-CD (LOCD)

\footnotetext{
${ }^{1}$ Department of Mechanical Engineering, University of Saskatchewan, Saskatoon, Canada (Corresponding Author Email: alf712@mail.usask.ca)

${ }^{2}$ Department of Mechanical Engineering, University of Saskatchewan, Saskatoon, Canada

3 Drug Design and Discovery Group, College of Pharmacy and Nutrition, University of Saskatchewan
} 


\section{1- INTRODUCTION}

Finding a cure for cancer is among the major challenges facing human health today because more than 200 types of cancer threaten human life [1]. Based on the World Health Organization (WHO) bank, approximately 14.1 million new cancer cases, and 8.2 million deaths from cancer were reported in 2012 worldwide [2]. This amount accounts for $14.6 \%$ of all global deaths that year [3]. This organization had also estimated the annual financial costs of cancer treatment in 2010 at approximately $\$ 1.6$ trillion.

In recent years, the total number of patients dying from cancer has escalated. Among them, the highest prevalence of cancer, belonging to the United States, is 1.5 percent of its population over five years. One percent of Japanese, 7\% of Eastern Europeans, and 4\% of Latin Americans have been affected by cancer for the past five years or more and kept living with it [4]. According to the American Cancer Society's predictions for 2025 [5], 16 million people will be affected by cancer, and 10 million will succumb to the disease. That is roughly 28,000 deaths each day due to cancer.

Cancer is the second most frequent cause of mortality in the United States after heart disease, accounting for one in every four deaths. Unless strictly essential measures are taken into account to prevent the disease from escalating and spreading over the next ten years, 85 million people will die of cancer [6]. Therefore, numerous attempts have been made to control the disease because physicians believe that timely diagnosis is the most vital factor that makes cancer treatment possible in the majority of cases. Therefore, it is conceivable to prevent an increase in the incidence of this deadly disease because more than $40 \%$ of cancer cases can be preventable in case of early detection, and a third of such patients can be definitively treated. For other non-curable patients, supportive therapies will drastically benefit them to improve their life quality. Various methods have been devised to diagnose cancer. A number of them can detect cancer by examining cancerous tissue and imaging, recently known as destructive procedures. In the following section, we will introduce the new approaches in this field.

The human body consists of millions of cells that create tissues such as muscles, bones, and skin. Most natural cells grow and reproduce in response to stimuli received from the inside and outside of the body and eventually die. If this process occurs properly, the body will remain healthy and maintain its normal function, but problems initiate when a natural cell mutates and turns into a cancer cell [7]. The number of cells in a tissue is determined by the balance between cell division and cell death. When the body needs it, the cells split into two and replace those defective cells or end their lifespan. 
Such a phenomenon makes it possible for the tissues to preserve their shape and their respective functions over time.

Cancer refers to a group of diseases involving abnormal cellular growth that can potentially spread and threaten other tissues. Cancer starts from damage in the cell's genetic material or Deoxyribo Nucleic Acid (DNA), responsible for the cell shape and function [8]. This DNA damage or alteration in a gene is called "mutation" $[9,10]$. When a cell's DNA changes, that cell varies from its adjacent healthy cells and no longer behaves like normal cells in the body. This altered cell separates from its neighboring cells, and the cessation of growth and its death is unpredictable. The aforementioned cell neither follows the internal instructions supervising the other cells nor acts in harmony with other cells. In other words, the appearance and function of cancer cells are different from those of healthy cells [11].

There are many different things that can cause mutations. An ordinary cell may turn into a cancer cell for no obvious reason; however, it is mainly caused by repeated exposure to toxic agents, chemical products, radiation, unhealthy behaviors, and poor diet $[12,13]$. These damages are usually detected and repaired before the cell can divide, but some may be ignored and transferred to daughter cells. These cells do not obey any rules and will divide even if they do not receive appropriate signals. So, cancer results from the accumulation of many mutations of genes, and happens over a long period, over many rounds of cell divisions, which explains why cancers are more common in older people.

When the mutant cell divides into two new mutated cells, the uncontrolled process continues in the same way until the earlier cancer cell ultimately multiplies to a mass of cells called tumors. Sometimes these tumors are benign and do not develop. Benign tumors are slow-growing and constrained by surrounding connective tissues, so they do not spread to other organs. Conversely, in case the tumor cells grow, divide, and destroy the natural cells around themselves and invade other parts of the body through the vessels, it is considered a malignant tumor.

The critical hazard of malignant tumors is their ability to invade healthy tissues and spread throughout the body. This multi-stage process in which cancer spreads inside the patient's body and involves several parts of the body is known as cancer metastasis. The more the tumors grow and enlarge, the more they block the supply of nutrients and oxygen to healthy cells. So, healthy cells will die when cancer progresses, and then the patient's function and health are compromised. Failure to stop this process can lead to death. Therefore, cancer refers to a set of diseases originating from uncontrolled cell reproduction. 
Meanwhile, isolated cells from the original tumor or cancer tissue are scattered throughout the body by blood flow or lymph, also called Circulating Tumor Cells (CTCs). These cells can then invade other parts of the body, multiply and produce new tumors in the new location. These cells can travel to the body's vital tissues through the bloodstream, which is one of the most general ways cancer can lead to death [14]. In fact, these cells cause cancerous tumors in different locations of the patient's body [15]. Because they can generate new tumors with similar or different properties from the primary tumor as soon as moving to a new location [16], diagnosis and interpretation of these unruly cells can define the incidence and the rate of cancer progression in the body. In other words, the outbreak of cancer in the body and its progression percentage is feasibly determined by monitoring CTCs. As expected, by analyzing the CTCs' genetics and observing drugs' treatment efficiency, valuable information can be attained to prevent cancer from spreading and eliminating the mentioned above cells $[17,18]$.

CTCs were first identified by Thomas Ashworth in 1869 in the patient's foot vein, far away from the primary tumor. According to his findings, these cells cause cancerous tumors at different spots in the patient's body [15]. However, the importance of studying cancer cells goes back to the 1990s. In this decade, Allard and his colleagues [19] observed CTCs in metastasis's primary stages. The critical point that should be reminded again here is that CTCs play a fundamental role in beginning the metastasis process.

The conventional technique for investigating cancers is sampling tumor and patient tissue. Patient sampling suffers from disadvantages so that it is crucial to discover new approaches in this domain. Whereas, this approach is a destructive procedure, and the patient cannot experience multiple sampling. Besides, this method cannot provide a measure of the treatment usefulness and the disease progression. In contrast, blood sampling holds many positive aspects, including measuring disease progress, verifying the treatment approach, the repeatability of the test, and non-destructive testing. In addition, unlike tumor sampling, this repeatable procedure is much easier for specialists and sufferers. Because of the CTCs' presence in the bloodstream, a simple blood test can accurately detect them. Despite counting and identifying CTCs, separating them is not as easy as it may seem. The problem with assessing such cells in the circulatory system is their much lower number than other cells [20]. Whereas one milliliter of adult human blood contains 5 billion red blood cells and 4,000 to 11,000 white blood cells [21], approximately 10 to 15 CTCs are only available in the same amount of patient's blood suffering cancer at the metastasis stage $[22,23]$. This issue complicates their counting and makes it extremely difficult to separate these limited numbers from the large population of the red and white blood cells. 
The CTCs' promising point is possessing different biochemical and physical properties than blood cells. Most CTCs have different surface proteins in comparison to the blood cells and are larger as well. While blood platelets and red blood cells are about 5 and $8 \mu \mathrm{m}$ in diameter, respectively, and white blood cells estimated between 10 and $15 \mu \mathrm{m}$, the average size of CTCs is 15 to $25 \mu \mathrm{m}$. Because of these differences and features, microfluidics devices have been considered a precise and appropriate instrument for CTCs separation from other blood cells over the last two decades [24]. Such systems can operate with a small volume of fluid (10-8-10-9 liter) for various experiments in the fields of biotechnology, engineering, chemistry, physics, and so on. Microfluidic systems are extensively adopted in capillary electrophoresis, isoelectric centralization, immunoassay, flow cytometry, sample injection in mass spectrometry, PCR amplification, and DNA analysis, cell isolation and manipulation, and cellular modeling. The research applications of microfluidic systems are chiefly related to the study of resistant bacteria to antibiotic drugs, the transfer of nanoparticles in the blood, and the kinetic investigation of chemical reactions. These devices measure the molecular diffusion coefficient, viscosity, fluid alkalinity, and chemical bonding coefficients. Diagnostic usages of microfluidic systems are cancer and pathogen detections. In the pharmaceutical industry, microfluidic systems have many analytical applications in biological products, such as improving and controlling medicinal protein products and experiments containing human cells [25].

The employment of the micro-scaled devices originates from the fact that the fluids behave differently on small scales than macro orders [26-28]. This different behavior is due to the domination of forces such as viscosity and surface tension, generally ignored on macro scales [2931]. Microfluidic devices enjoy positive attributes such as low cost, low sample size, portability, high accuracy and sensitivity, the ability to integrate multiple technologies, and short experiment time for cell separating, classifying, and sorting, and so forth [32-34]. Furthermore, microfluidic devices, due to their small size, allow us to efficiently manage and observe the testing fluid. However, such devices' main advantage of consuming a small sample volume elevates their usage in medicine [1]. For example, the size reduction of conventional drug delivery devices to micro and nano scales makes it possible to insert them into the patients' bodies. As such, we can check the patients' health situation meticulously and devise preventive remedies from outside the body and apply them inside.

These devices can inject drugs at different doses continuously or intermittently over prescribed time intervals. Whereas in conventional drug delivery types, the drug may enter the body in higher or lower doses than required or at an inappropriate rate, which breed toxicity or low efficiency. Another most important use of microfluidic devices in the medical industry is separating, classifying, and sorting cells [27]. The measurement of stem cells in a microfluidic chip is much more accurate than 
in the conventional culture vessels. Miniaturizing measurement enhances the overall efficiency because it allows fluid control and precise biological simulation to work with stem cells in microfluidic devices [35]. In biological concepts, cell separation and sorting are divided into two types: the mass classification of cells and single-cell categorization. In the first type, cells are assorted into masses with common characteristics. While in the single-cell sorting, each cell is individually chosen and examined.

The first step in any categorization, whether in traditional or new technologies, such as lab-on-a-chip, is to screen cells based on one or more of the key features underlying the classification. Cells can be distinguished according to their physical properties such as size, density, or behavior in force fields such as electric or magnetic fields, or their resistance to chemical decomposition.

Classification can also be positive or negative. The target cells are separated based on the desirable traits and collected for subsequent positive categorization applications. Positive sorting is usually effective in isolation through flow cytometry. Positive sorting of individual cells using flow cytometry can accomplish high purity cell separation; still, each cell must be carefully examined prior to separation, and the most appropriate method is selected. This method has good efficiency and function and separates the cells with high purity as long as the target cell population is not infected with undesirable cells. The objective population's infection by unwelcome cells is common, especially when the favorable cells are in the minority. In the negative category, undesirable cells have characteristics to absorb and collect based on them. As a result, the target cells pass and exit without absorption [36]. Negative categorization is usually used in connection-based approaches such as antibody binding.

The target cells must be separated from the other cells in the sample once they have been detected. There are many ways to isolate cells based on microfluidics, which will be elaborated in the next section. The most significant breakthrough in microfluidic fields is the emergence of the lab-On-aChip (LOC) concept. The LOC is a set of micro-channels, micro-pumps, micro-valves, micro-mixers, and other components that a macro-scaled lab demands to perform and analyze the trials. As a minimal, portable, inexpensive, and disposable laboratory, this system is meaningful in medical fields [3]. In other words, if we consider the microchannel dimensions of about one-thousandth of a laboratory tube, the required material amount for testing through this system has been reduced by about one million times. For example, while a macro-dimension experiment consumes one liter of raw material, only one micro-liter of the sample is spent in microsystems. Therefore, this dramatic reduction minimizes both the amount of test material and the material added to the testing sample. 
On the other hand, the fabrication of these systems are inexpensive; the livability and biodegradability of applied material in such devices make them disposable. This property is an advantage in many experiments. For instance, in many blood tests, the sample contamination is probable; hence the test results will not be precisely defined [5], but the usage of a disposable device dramatically reduces the possibility of infection.

A particular type of LOC called Lab-On-a-CD (LOCD) has become increasingly widespread in recent years. In these systems, the microfluidic components are established on a rotating disc platform or CD. Therefore, the generated forces in a rotational platform (i.e., centrifugal forces) can be used as flow actuators inside microchannels; consequently, the system will no longer require any external accessories as a pump. Comparatively, the rotary devices controlling fluid flow have more inherent privileges than conventional LOC that employs micro-pumps to drive fluid. This subject reduces the design and fabrication cost, and the microfluidic scheme compression, which subsequently enables the implementation of more sophisticated operating units on LOCD that illustrates the difficulty and importance of working on such systems.

Since the centrifugal forces (due to the system rotation) link directly to the drive system rotational frequency, by changing the drive engine angular velocity, we can regulate these forces, promoting such devices' advantages. On the other hand, since the velocities and forces practiced to the fluid depend on the rotational frequency's second power, a much more extensive range of the required force for driving or stopping fluid can be chosen by changing the angular velocity. Additionally, centrifugal forces can be enlarged enough to overcome other forces, such as surface tension and capillary forces, and cause fluid flow. Moreover, by only using channel geometry, this force can be reduced to a point where other forces override it and prompt the fluid flow to stop. To clarify, we create a micro-scaled valve that is easily controllable and operational [37].

Furthermore, because of the disc's inertia, its rotational motion is self-stabilizing; therefore, the generated vibrations in the fluid pumping methods using pressure difference will vanish. Another advantage of LOCD is having centrifugal force independence of parameters such as viscosity, conductivity, $\mathrm{PH}$, and surface tension. These systems are substantially able to create and conduct the fluid flows with different physical properties, especially for biological liquids and laboratory reagents. The rotational motion generated by an ordinary, inexpensive rotary motor also eliminates the need for additional devices such as pumps and their other microfluidic connections.

Although the principles of centrifugal analyzer systems were established in the late 1960s, their implementation in microfluidic domains was first carried out by a few commercial organizations in 
the early 1990s [38]. Following the activities of these pioneering commercial companies, research and academic groups have developed numerous microfluidic processes, including volume measurement [39], gating [37, 40-42], mixing [43], flow orientation [44], and pumping of various fluids $[37,40]$, which have been mounted on centrifuge-based platforms and a CD.

In addition to the merits of fluid flow control, centrifugal microfluidic systems have other inherent advantages, including optical detection, over conventional lab-on-a-chip systems. This optical detection can be useful for counting particles or cells separated by a microfluidic separator. The fluid flow controller and detector systems can be assembled on a powerful macroscopic unit, such as an optical disc. As a result, an ordinary LOC device converts to a passive unit (optically and microfluidically).

Despite all the above advantages, these centrifugal microfluidic systems also have disadvantages. The most undesirable drawback, originating from the low volume and small quantity of the sample, is that this method is not suitable for isolating scarce cells from the testing instance. For example, it is difficult to directly detach CTCs in a patient's blood sample through this approach. To tackle this problem, a fixed-substrate separator is initially used to concentrate the target cells, and then the condensed sample will be placed on a disc for the next procedures.

\section{2- CELL SEPARATION TECHNIQUES}

As mentioned in the previous section, various methods have been developed to diagnose and treat cancer disease due to the increasing incidence of this illness. However, the problem is that because cancer is not a common illness and is a human body malfunction, it is difficult to reach one universal medicine. Each person is different, and they have different genes, different environmental influences, and habits. In other words, lung cancer in one person can be radically different from lung cancer in another. One of the most prominent of the recently introduced techniques is to discern cancer by isolating specific cells from one milliliter of human blood. When a living tissue suffers from cancer, some cancerous cells named circulating tumor cells (CTCs) separate from that tissue and enter the bloodstream. For diagnostic purposes, these cells can be counted to determine the stage of cancer growth. Hence, these cells must first be separated from the bloodstream. There are numerous reasons why separating CTC from the bloodstream for investigational purposes is necessary:

1- About ninety percent of the deaths due to cancer involves tumors that have spread around the body. Cancer's main strength can turn into a weakness by investigating the CTCs and 
removing them by a suitable approach. For example, CTCs examination can help fight cancer more effectively by purposely changing DNA in the immune system [45].

2- Scientists want to monitor how a patient's tumor responds to the treatment; if a blood sample shows signs of tumor after treatment, it means that the patient needs another type of treatment. Ultimately, CTC investigation can open up new ways to personalize each patient's care and help their doctors stay one step ahead of the disease.

3- Before choosing a suitable treatment, doctors must know everything about the cancer cells to control their development, because the complementary treatments will be used alone or in combination according to the type of cancer and its status. The conventional treatment acts not only on cancerous cells but also healthy cells and makes them die. Better knowledge of cancerous cells' characteristics makes it possible to develop therapists that target the cancer development mechanisms more specifically.

Having understood the importance of CTC separation, the problems for CTC isolation must be introduced. The conventional technique for investigating cancers is sampling tumor and patient tissue, but it has some negative aspects; for example, it is a destructive procedure so that the patient cannot experience multiple sampling, and it also cannot show the treatment success and the disease progression. In contrast, as another technique for investigating cancers, blood sampling holds many positive aspects, including the disease progress, the treatment verification, repeatability, and nondestructive procedure.

One of the questions might be why blood sampling has more advantages than tissue sampling. The answer would be because of the CTCs' presence in the bloodstream so that a simple blood test can accurately detect and demonstrate cancer types. Although examining CTC will help researchers distinguish cancer and find its treatment, counting and identifying CTCs and separating them from the patient's blood is not as easy as it seems. The problem is their much lower number compared to the other cells. There are 5 billion red blood cells and 4,000 to 11,000 white blood cells in one milliliter of human blood, and approximately 10 to 15 CTCs even at the metastasis stage. So the low number makes it too complicated to separate these limited numbers from the large population of the red and white blood cells. Nevertheless, different biochemical and physical properties of CTCs than the other blood cells can be regarded. CTCs are usually larger than the others; while red blood cells are about 6 to $8 \mu \mathrm{m}$ in diameter, and white blood cells are estimated between 10 and $15 \mu \mathrm{m}$, the average size of CTCs is 15 to $25 \mu \mathrm{m}$. Such different feature provokes researchers to employ microfluidic devices to separate such cancerous cells from the whole bloodstream. 
This review article presents papers and research that have already been employed to fabricate cell separation devices. According to the common points among the methods and their integration, it is possible to classify them differently. Firstly, cell labeling methods are expressed. Then, the traditional non-micro-scaled separation methods are described. In the following, devices made for the separation of CTCs in micro dimensions using microfluidics concepts are divided into two categories: active classification (applying external force field on cells) and passive classification (separation during fluid motion based on the generated hydrodynamic forces) [46].

All these methods focus chiefly on enhancing accuracy and increasing the cancer diagnosis speed. Three essential parameters are usually noted for the isolation of cancer cells:

1- Method efficiency is defined as the number of isolated cancer cells to the total number of cancer cells in the blood.

2- Isolation speed determines the maximum inflow to the microchannel so that the device's efficiency does not decrease significantly and can isolate cancer cells. In these methods, if the flow rate exceeds a certain amount, either the cancer cells are damaged due to high shear stress, or the device's efficiency is low.

3- Separation resolution: The first definition is the number of different groups of particles (based on their sizes) separated from different outlets. The second definition states that separation resolution means the distance of isolated particles at the microchannel exit.

\section{2-1- Cell labeling methods}

Cell labeling methods for separating distinctive cells are complementary and not specific to the micro or macro scale. Regardless of the dimensions (micro/macro) of the separation devices, this method can be used in all separators along with other isolation techniques. Cell labeling is employed to mark the particular cells and facilitate their identification and separation. Such isolation is performed based on the cell's biochemical properties. To be specific, separation can proceed based on different surface markers of the cells.

In this method, particles with desired electrical and magnetic properties are coated by an absorber of cell surface characteristics. These absorbers interact with the cell surface markers; as such, particles are attached to the cells. The external field is then applied to the sample according to the 
particles' property. Therefore, the cells can be controlled and transferred by such particles in electrical, magnetic, or acoustic fields [47].

The separation of cells with functionalized particles' aid depends on the particle material, size, and ability to connect to the desired or undesirable cells. In some cases, the channel's inner surface is coated with these functionalized particles so that the isolated cells are trapped when they pass through the channel [48]. This method's application will be elaborated more in the separation section by applying magnetic and electric fields. Cell labeling is valuable in cell separation techniques; however, this method should be more cautiously employed due to the Cancer Stem Cell (CSC) hypothesis and similar cell surface features. The CSC hypothesis states that particular cells in the tumor can multiply, develop, and turn into various cancer cells. CSCs have properties similar to stem cells and can produce a new tumor even after various treatments have removed the primary tumor. In the traditional approaches, the tumor was eliminated without regarding CSC, while CSCs can cause the recurrence of disease after tumor removal. Oppositely, CSCs are first targeted in modern methods, and the rest of the tumor will then be treated [49].

\section{2-2- Common non-microfluidic cell separation devices}

Among all the non-microfluidic methods designed to separate cells, only a few of those have a suitable performance and are still in use. Some of the most important ones, such as flow cytometry, membrane filter, and separation of cells through the centrifugal forces and magnetic field, which are still usable and applicable, are elaborated in subsequent sections.

\section{2-2-1- Fluorescence-activated cell sorting (FACS)}

The usage of flow cytometer devices is the most well-known technique by which cells with low frequency are differentiated. Cytometry means measuring and analyzing different cellular components in a sample. The flow cytometer device identifies various cell components and counts them simultaneously. In this method, cells are first labeled with monoclonal antibody attached to fluorescent or fluorochromes connecting to cell components. These painted cells with fluorescent colors are then arranged and concentrated in the center of a microchannel by hydrodynamic techniques and individually transmitted in front of the laser beam. Subsequently, the light is 
scattered directly (Forward scatter) or perpendicular to the laser beam axis (Side scatter) and is then collected by the detectors (Figure 2-1).

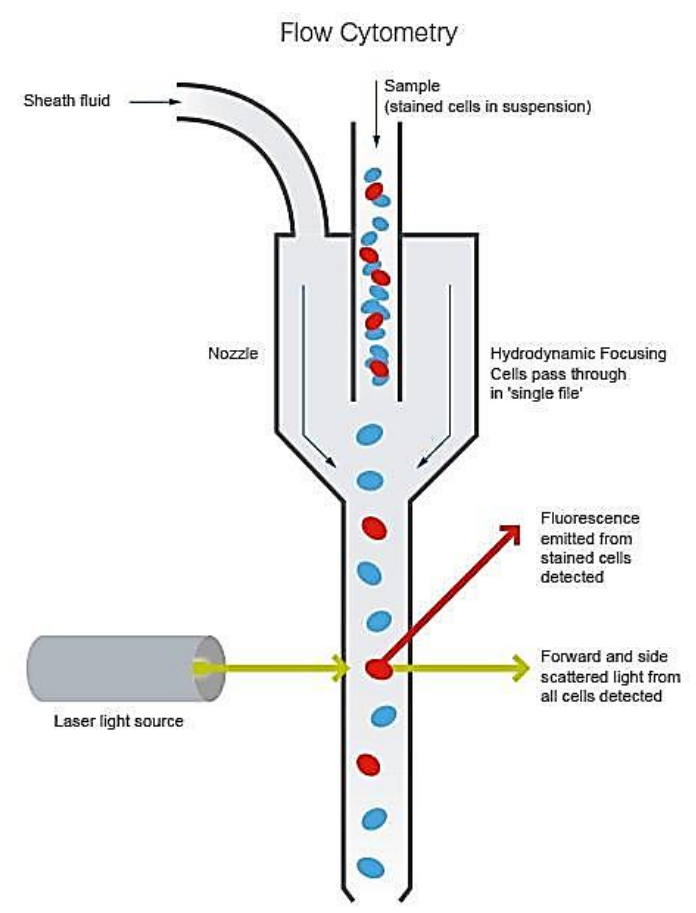

Figure 2-1: Overview of diagnosis section of the flow cytometry device, Sheath fluid focuses the cell suspension, forcing cells to pass through a laser beam one cell at a time. The forward and side scattered light is detected, and fluorescence is emitted from stained cells.

Optical signals are obtained due to the laser beam to the cells and their size and internal structure. The collected light can then be converted to the equivalent electrical signals by the Photomultiplier tube (PMT). Receiving and detecting such electrical signals is carried out by employing detectors [48]. Light scattering at various angles can differentiate cells based on differences in size and internal complexity. In contrast, the scattered fluorescent light from a fluorescently labeled antibody can differentiate cells based on differences in surface and cytoplasmic antigens. Consequently, cells are distinguished based on characteristics such as volume, granulation, and colorability rate. Although the cells move concentratedly and individually inside the microchannels in front of the light beam, they can be isolated up to 100,000 cells per second through this method [50].

FACS, based on the flow cytometer, was first invented in 1960 and has undergone many changes to date [48]. In basic FACS methods, each cell is trapped in an aerosol droplet having a specific electrical charge. Detectors then separate the droplets based on their electrical charge [47]. Many attempts have been made to eliminate this step due to droplet creation problems. These efforts led to the 
design of the first FACS device adopting a microfluidic chip in 1999. The $\mu$ FACS device (Figure 2-2) [43] has a lower manufacturing cost than large-dimension devices and has higher accuracy.

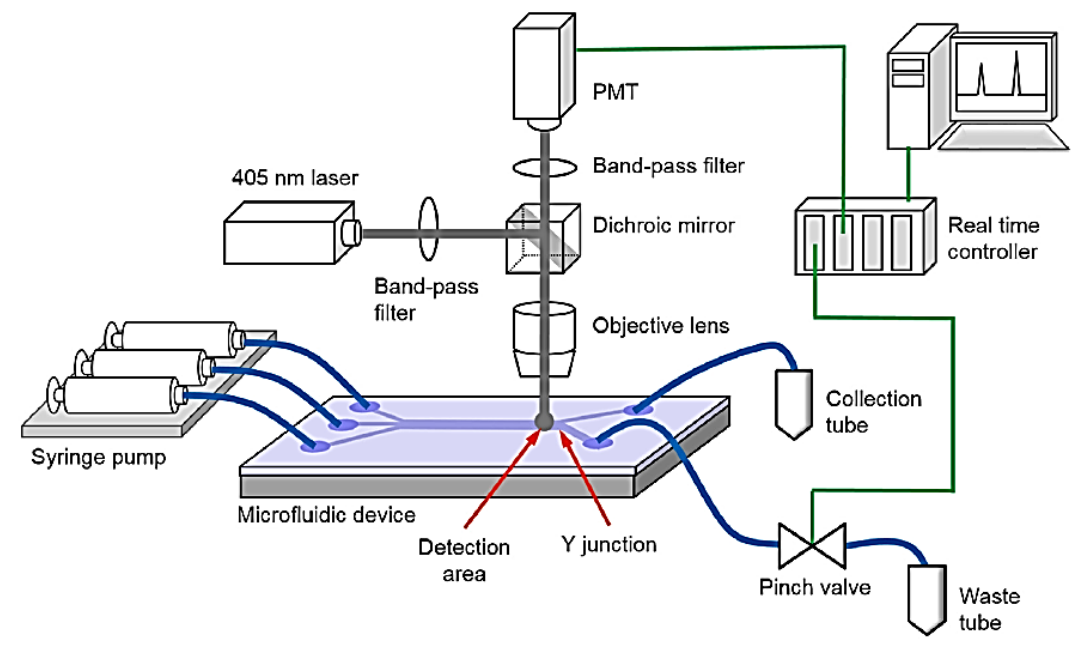

Figure 2-2: The cells are settled in an electroosmosis solution and controlled by platinum electrodes. A Laser beam radiating on the solution stimulates the fluorescent. Fluorescent radiations are then collected by a microscope and measured by photomultiplier tubes (PMT). The computer receives signals from the PMT and adjusts the voltage to control the electroosmosis fluid [51]

This device was first employed to separate painted E.Coli bacteria from its colorless type [52]. The pulsed lasers have been used in the device fabrication to produce propellant bubbles that push cells towards the separation channel, increase the FACS operation speed, and enhance the efficiency [53]. Isolation of CTCs has been performed by applying the FACS method for patients with bladder cancer through their urine samples [54]. FACS has also been recently used in infertility tests for sperm separation [55]. This method also has some drawbacks, such as expensive devices, required materials for each test, microchannel clogging, and sample contamination. Although flow cytometry suffers from the disadvantages mentioned above, it is the most common procedure in laboratories. Some of the main reasons for utilizing such a method are:

1- Flow cytometry devices help identify and count a small number of cells, even among many other cells.

2- This device is time-efficient to count a large number of cells in a short time. The collected information about each of these cells can be beneficial in subsequent studies.

Furthermore, this method has also been recently applied in some microfluidic devices. These microfluidic devices usually consist of a bifurcation region separating the detected cells by optical 
forces [52], electroosmosis [56], or hydrodynamic forces [57, 58]. However, such microfluidic devices have not been sufficiently developed to supersede the conventional flow cytometry methods.

\section{2-2-2- Centrifugal devices}

The most conventional method for isolating cells and blood components is the centrifugal approaches. The basis of separation in this method originates from the different density of cells. Density gradient centrifugation can be used as a separation technique to isolate the CTCs and as a measurement method to estimate the densities of particles or molecules in a mixture.

In this method, the patient blood sample is first blended with an anticoagulant solution to not coagulate during the separation process. The blood is then transferred to a centrifugal device and spun at a specific speed. The centrifugal force causes the cells with high density to move further away from the rotation center. As a result, having a higher density, the red blood cells are placed at the lowest point, and the white blood cells and plasma are respectively settled on the hematocrit (Figure 2-3) [59].

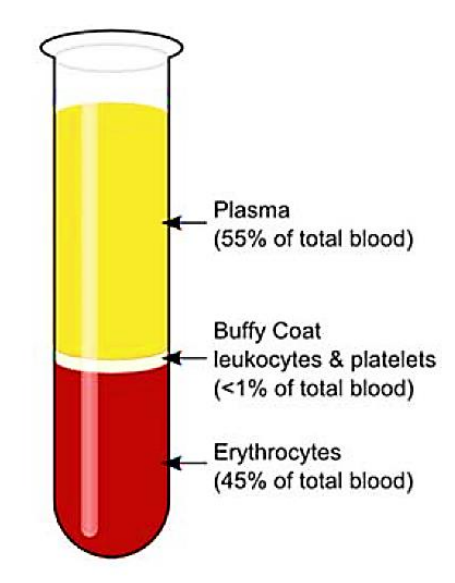

Figure 2-3: Blood components after centrifugation

One of the most well-known techniques in separating blood cells through the centrifugal concept is the Ficoll method. In this method, red blood cells are deposited on the bottom of the tubes after centrifuges, while nucleated cells are placed on the red blood cell surface in the form of rings. Plasma also appears on the highest layer. Ficoll method has also been practiced to separate CTCs. Meanwhile, the centrifugal devices have some limitations as well. For instance, due to stress and shear stress on 
cells during rotation, there is a possibility of cell loss or changes in their properties. It is also impossible to detach blood cells with a very small frequency through this method [60].

One of the most crucial things that facilitated centrifugal separation was reaching the RosetteSep® solution. The RosetteSep ${ }^{\circledR}$ solution containing a series of antibodies is added to the blood and causes the accumulation of white and red blood cells and a clot formation. Subsequently, the clots are deposited owing to the centrifuge, and the target cells can be easily separated (Figure 2-4) [32].

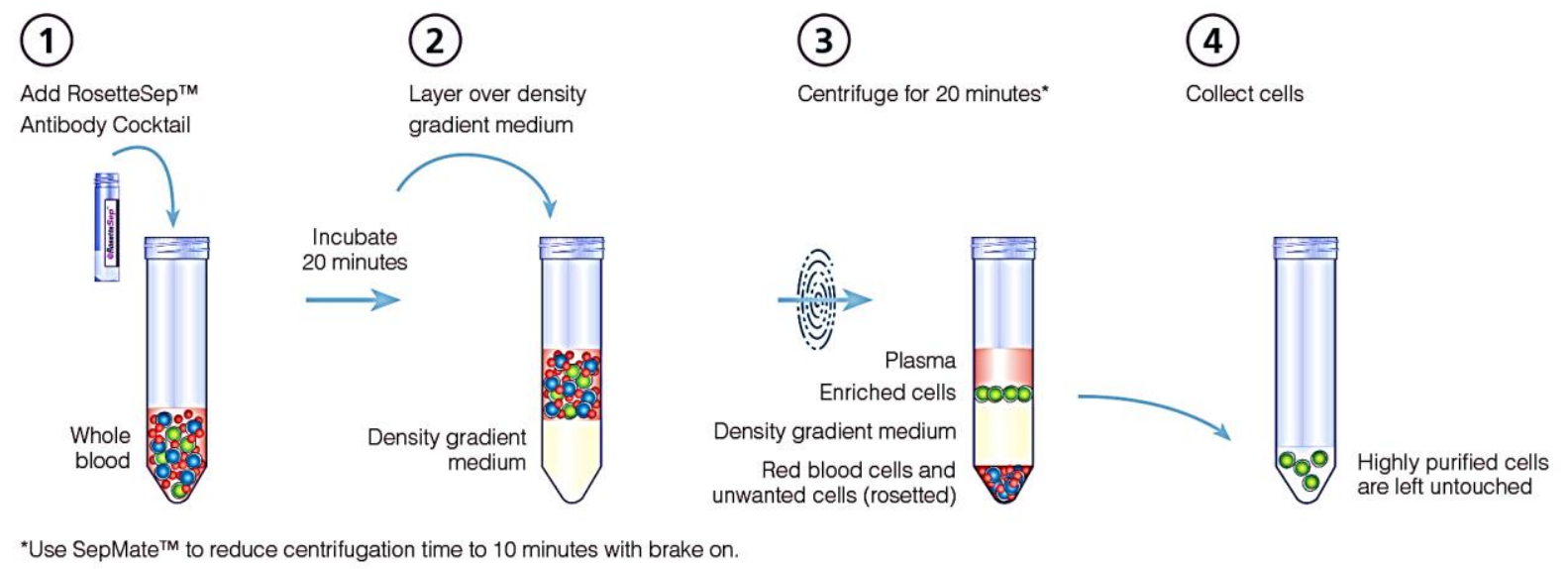

Figure 2-4: Blood separation through centrifugation 1) RosetteSep antibody solution is added to the blood 2) The adequate time is considered for the blood cells to coagulate with the help of the antibody solution 3) The sample is centrifuged, and the different layers of blood are then separated 4) Target cells can be extracted [54]

\section{2-2-3-Separation through membrane filters}

Separation of cells based on the size and flexibility is one of the oldest methods due to its visibility and easy process controllability. One of these methods is filtering. Among these, membrane filters are one of the most authentic models of filters. The principle of cell separation from the main flow through membrane filters is quite simple. The membrane acts as a filter that will let blood flow through, while it catches CTCs and isolates them individually based on their size and deformability. However, it is worth noting that the membrane filtration method is less applicable than the centrifuge method.

In this method, similar to the centrifuge method, the blood sample is first mixed with an anticoagulant solution to not coagulate during the separation process. The diluted blood next passes through a 
membrane. This membrane causes larger cells than a threshold to be trapped while smaller ones continue on their path and are separated (Figure 2-5). Membranes are also made of various materials.

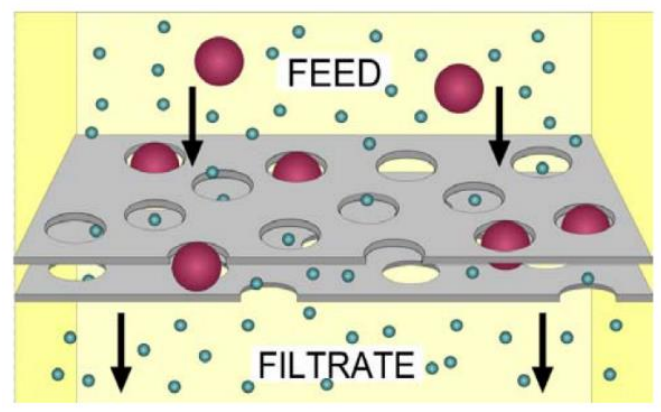

Figure 2-5: Overview of membrane filtration method

The common problems in using membrane filters are the possibility of clogging, the need for periodic maintenance and regular cleaning, and the cells' inability to recover after filtration. Such a method's most undesirable drawback is that it cannot separate more than one particle type in one step.

A number of them have already been commercialized, such as Cell Microsieves® and ISET®. For example, the filter of Cell Microsieves ${ }^{\circledR}$ is manufactured of pure nylon and has cavities measuring 5 to 200 microns. The possibility of sticking cells and proteins to the filter and its clogging is reduced because the filter's extractants and detergents are paint-free. ISET® stood for Isolation by Size of Epithelial Tumor cell was developed to separate isolated Epithelial cells from tumors. Its name briefly refers to the isolation of epithelial cells based on size. This device, having cavities as small as 8 microns, can work with a small volume of patient blood samples (only $1 \mathrm{ml}$ ) [61].

\section{2-2-4- Separation of cells through the magnetic field}

As an essential method for cell separation, the magnetic field (magnetophoresis) usage, while having the same fundamental principles and similar separation considerations, applies to microfluidic and non-microfluidic devices. Due to the cells' low magnetic permeability, the Magneto-static forces can highly selectively separate cells tagged with magnetic nanoparticles without interference from either the surrounding electrolyte solution used for cell suspension or the rest of the cells [62].

In this method, magnetic particles coated with an antibody are used. These particles are attached to the specific antigens at the cell surface. First, the magnetic particles are well covered with antibodies 
and then mixed with the cells and incubated. The mixture of the cell and the magnetic particles then enter the separator, and the particles containing target cells are also collected by a magnet [32].

The first commercial magnetic separator was the MACS1 (Magnetic Activated Cell Sorter) developed by Miltenyi in 1990, which used magnetic gradient columns. The target cells accumulate near the column walls where the magnets are located, and the flow carries the rest of the cells. Then the accumulated cells on the walls can be easily washed and collected from the device. At the output of this device, the target cells' concentration is $10^{5}$ times higher than the primary sample [63]. The device was equipped with a magnetic broom, which was a magnet that moved slowly in the sample, in subsequent research to increase efficiency [64]. The most significant achievement in the magnetophoresis field is fabricating the Cell Search® device. Figure 2-6 is one of the most wellknown methods of identifying, distinguishing, and separating CTC.

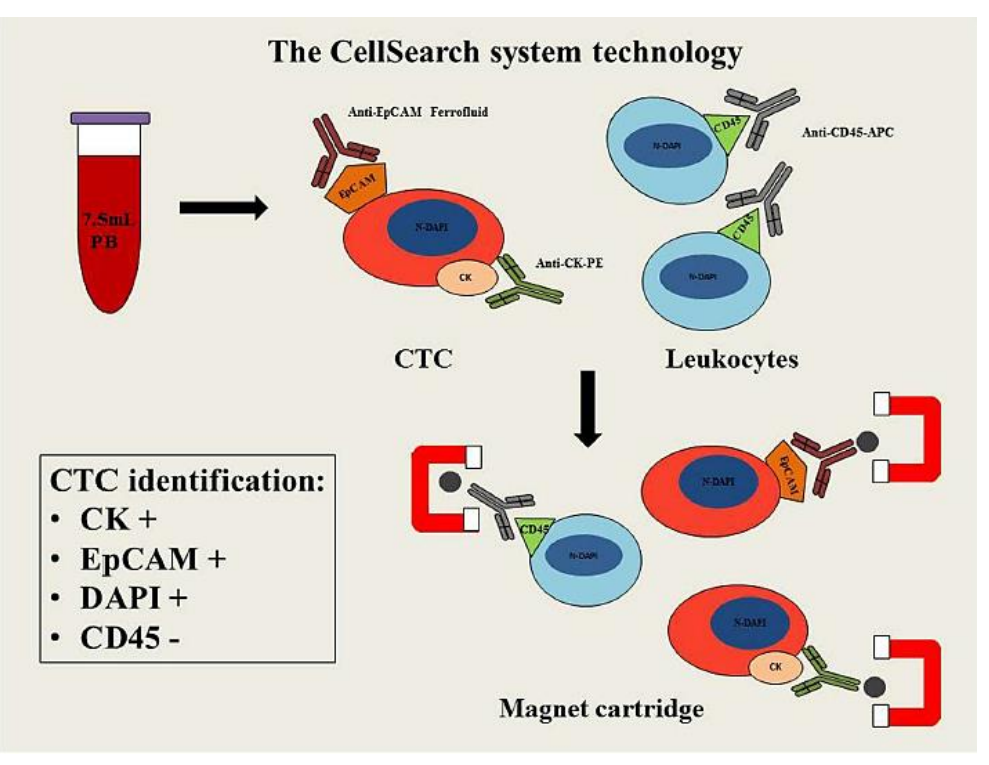

Figure 2-6: Cell Search $®$ device and the process of its positive and negative separation, CTCs are absorbed by magnetic particles containing two types of antibodies, and another antibody absorbs white blood cells. Ultimately, the cells can be isolated with high purity by applying the magnetic field [65]

This device, which detects CTCs by immunohistochemistry, is currently the first and only device approved by the US Food and Drug Administration (FDA). Cell Search ${ }^{\circ}$ device, commercialized in 2000, is used for various cancers such as breast, intestine, and prostate. After entering the $7.5 \mathrm{ml}$ patient's blood samples to the device, samples with at least 5 CTCs for breast and prostate cancers, and at least 3 CTCs for intestinal cancer are detected [65]. 


\section{2-3- Microfluidic cell separation devices}

This section is an overview of cell separation devices made in the microfluidic field. Microfluidic devices generally enjoy some significant advantages: low cost, low sample size, portability, high accuracy and sensitivity, the ability to integrate multiple technologies, and short experiment time for cell separating, classifying, and sorting, so on. It should be noted that the general principles and physical fundamentals of separation are quite similar to the non-microfluidic devices in many cases. However, the system's dimensions have been decreased to the micron to reduce fabrication costs and the required sample, while increasing the accuracy.

\section{2-3-1- Active Cell Separation Devices}

In active separation systems, external forces are used to control and manage the cells. According to the applied force nature for isolation, active separation systems are sorted into four general categories:
A. Isolation adopting electric fields (Dielectrophoresis) [66-71]
B. Isolation employing acoustic waves (Acoustophoresis) [72-74]
C. Isolation by applying magnetic fields (Magnetophoresis) [75-78]

These devices not only can control the cells precisely but also possess a relatively high operational speed.

\section{2-3-1-1- Isolation through electric field applications}

Isolation with the help of the electric field can be done in two ways: electrophoresis and dielectrophoresis. In the Electrophoresis approach, the particle displacement is caused by the electric field effects on their net free charge. Therefore, this method is based on the surface properties of the cell membrane. Most cells have a negative surface charge in physiologic $\mathrm{PH}$; this charge density is different from one cell type to another and results in different electrophoretic mobility in an electrical field. Among several cell electrophoresis methods, free-flow electrophoresis (FFE) is the most widely used method. In FFE, the cells running in a buffer with a controllable flow rate are deflected based on their charge and collected into tubes. Although this method has been used to isolate viruses and bacteria from eukaryotic cells, the surface net charge is not a good criterion for separating a mass of cells with relatively similar properties. Hence, Dielectrophoresis was introduced to address the 
electrophoresis's constraints. Dielectrophoresis refers to the net migration of polarized particles due to interactions with an electric field gradient and depends on the cell wall, membrane, and cytoplasmic electrical properties [79].

As a separation technique, Dielectrophoresis lies in differences in particle size and polarizability. Particles become polarized when electrical fields are applied to them. In turn, this induced polarization interacts with the applied field, resulting in each particle experiencing a unique net electrical force. This net force's magnitude depends on the particles' dielectric characteristics (how easily the cells are polarized and how big they are), the electrical field frequency and strength, and the fluid medium's electrical properties. Therefore, Dielectrophoresis (DEP) utilizes the difference in healthy and cancerous cells' polarizability degrees and their size for separation [66-71]. The sample is placed in a non-uniformly electric field to achieve such a polarizability difference [66]. When a nonuniform electrical field exposes to dielectric particles, a force in the direction or opposite direction of the electric field gradient is applied.

The most significant advantage of such a method is no need for particles to be charged so that any dielectric particle in a non-uniform field becomes dipole and oriented. However, the strength and direction of the generated force by the electric field depend on the particles' dielectric properties (their polarization when exposed to a current), their size and shape, the electric field's frequency and intensity, and the electrical properties of the fluid (Figure 2-7) [80-82]. Dielectrophoresis devices make the CTCs separate through their different properties, such as their size and dielectric properties compared to the other blood cells.

The electrodes usually absorb and attach the CTCs to themselves while the rest of the blood cells continue moving along with the flow to leave the device. As shown in figure 2-7, cells were injected into the chamber by syringe and allowed to settle before the flow was initiated from the gear pump. Also, an AC electrical signal was applied to the electrode to influence the cell elution characteristics. This method's valuable benefit over the other conventional methods is that the cells can be captured without being damaged during the separation process. 

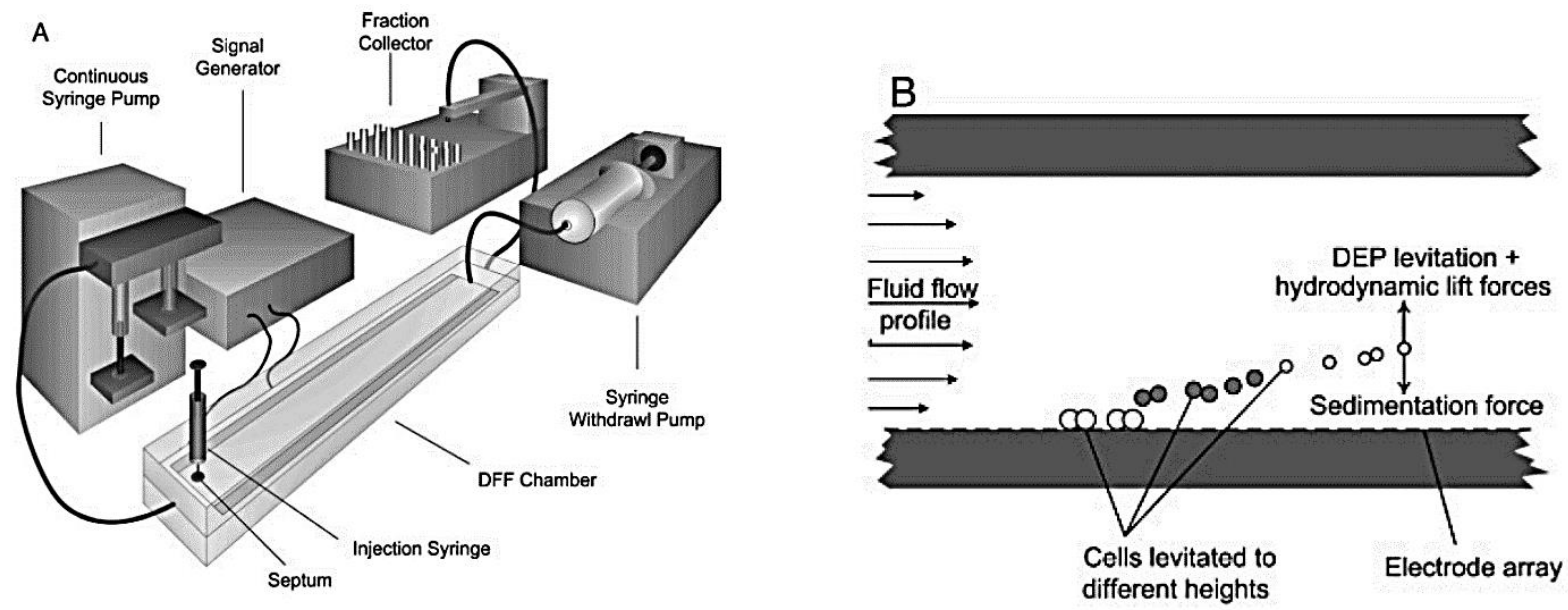

Figure 2-7A: Dielectrophoresis Separator, The cells are injected into the device by a syringe pump and allowed to be deposited. An electric current is then applied; Figure 2-7B: the cross-section of the channel has been identified, where the forces acting on the particle ultimately determine its equilibrium position) [83].

Due to the difference in the particles' electrical conductivity and their surroundings, some particles move towards increasing the field density, called positive electrophoresis. In contrast, the others start transferring towards decreasing the field density, named negative dielectrophoresis. The view of such separation is shown in Figure 2-8.
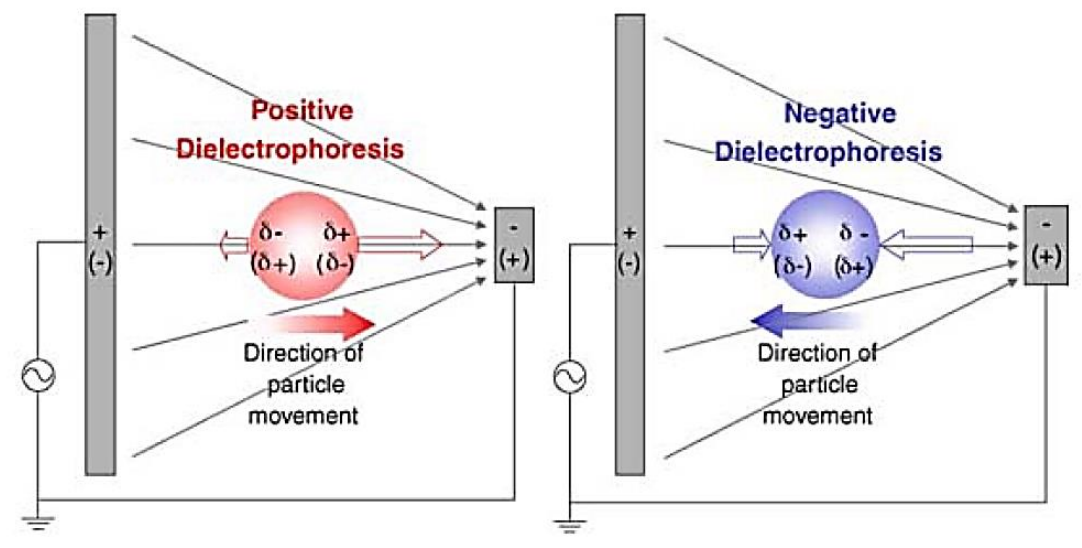

Figure 2-8: Overview of positive and negative dielectrics in a non-uniform electric field [84]

Therefore, when an electrical field is applied to particles, they become dipole. The difference in the polarization degree of healthy and cancerous cells makes the net electric force on each particle unique; thus, cancerous and healthy cells are located in different places in the presence of an electric field. For example, as shown in Figure 2-7B, all cells are subjected to two forces, a lift force and a force 
originated from an electric field. Under such a circumstance, more electrical force is applied to the cancerous cells; therefore, they are more willing to move towards the lower plate and settle at a lower height than healthy cells. The next method, shown in figures 2-9, is a combination of the separation methods originated from the differences in size and the polarization degree in electric fields. As illustrated in this figure, fluid first passes through several pores to initially separate some of the cancerous cells, and the remaining cancerous and healthy cells exit through two different outputs under an electric field [85].

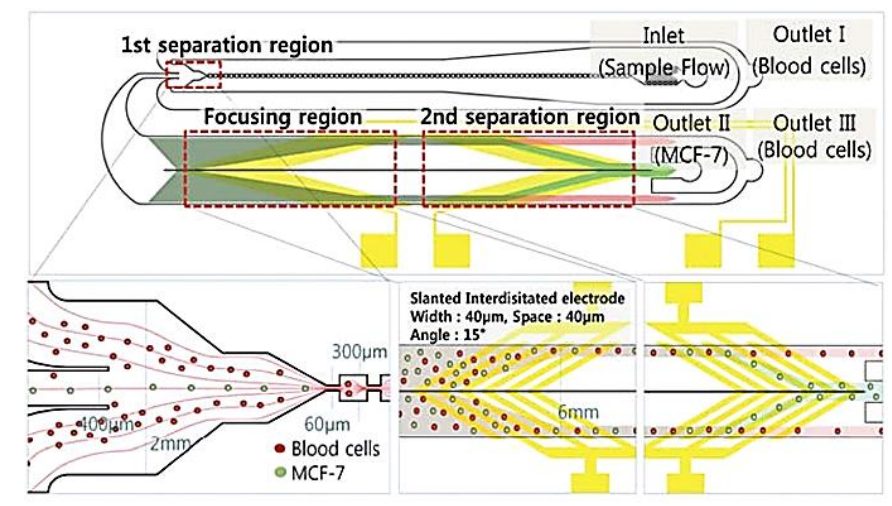

Figure 2-9: Separation using differences in the particles' polarization characteristics under an electric field

The separation method's main advantage is the difference in dimensions and sizes in the output rate or so-called test speed. The primary dielectrophoresis method's benefit is the relatively high purity percentage of the isolation cells. Therefore, the advantage of both methods is applicable by this method so that the device enjoys both the adequate output advantage and a high purity percentage. Furthermore, such a device can separate different types of cells from each other. For example, this method can accurately isolate the bacteria or cancerous cells from the bloodstream [86, 87].

The dielectrophoresis device can profit from the continuous and alternative electric current. For the lab on the chip, which alternating current (AC) is favorable, various electrodes arrangement is used. Electrodes are angled and placed in different convergent and divergent arrangements to prevent them from stopping the flow [88]. It is worth mentioning that this method's main advantage compared to flow cytometry methods and separation by means of the magnetic field is that there is no longer a need to label cells; Hence, it has less difficulty and is more affordable [24, 89].

Gascoyne et al. at the University of Texas in 2008 developed a device that can detect and separate breast cancer cells in the MDA-MB-468, MDA-MB-435 MDA-MB-231 categories from a sample having 
30 million blood cells. Their device had larger electrodes than previous devices; consequently, a larger sample could be entered and processed at a higher rate [83].

As mentioned earlier, dielectrophoresis techniques make it possible to collect and re-culture cells for the next usages, including drug testing. In addition, the electric current has also been applied to examine and test drug effectiveness and efficiency. For example, the effectiveness of Arsenic trioxide $\left(\mathrm{As}_{2} \mathrm{O}_{3}\right)$, which is currently used in blood cancer treatment, is accurately measured. Therefore, different amounts of $\mathrm{As}_{2} \mathrm{O}_{3}$ are injected into the Dielectrophoresis activated cell sorter (DACS) containing the K562 class blood cancer cells. Subsequently, the drug's effect on the cells is determined by isolating living cells from other cells and examining their death rates. The appropriate concentration and time intervals for having satisfactory drug effectiveness are determined in this way [90].

The most prominent commercial cell separation device enjoying dielectrophoresis benefits is the Apo cell $囚$ device. Apo cell@, introduced in 2009, can separate CTCs from blood without labeling requirements because it can work based on their dielectric property differences [91]. One of the challenging issues while using this method for separating cells from each other is that the dielectrophoresis force is highly dependent on cell size. Most blood cells are only about $10 \%$ different in size and usually have similar electrical properties. Besides, the dielectrophoresis phenomenon is highly dependent on the electrical conductivity coefficient of fluid; however, the separation of particles from each other in physiological buffers is difficult due to their high electrical conductivity. Heat effects should also be considered in applying this method to isolate cells because a fluid temperature with a high permeability coefficient increases when exposed to an electric field. This temperature increase, known as the Joule heating effect, can damage cells [89]. Doh and Cho succeeded in isolating live yeast microorganisms from the dead ones by this method (Figure 2-10) [84]. 


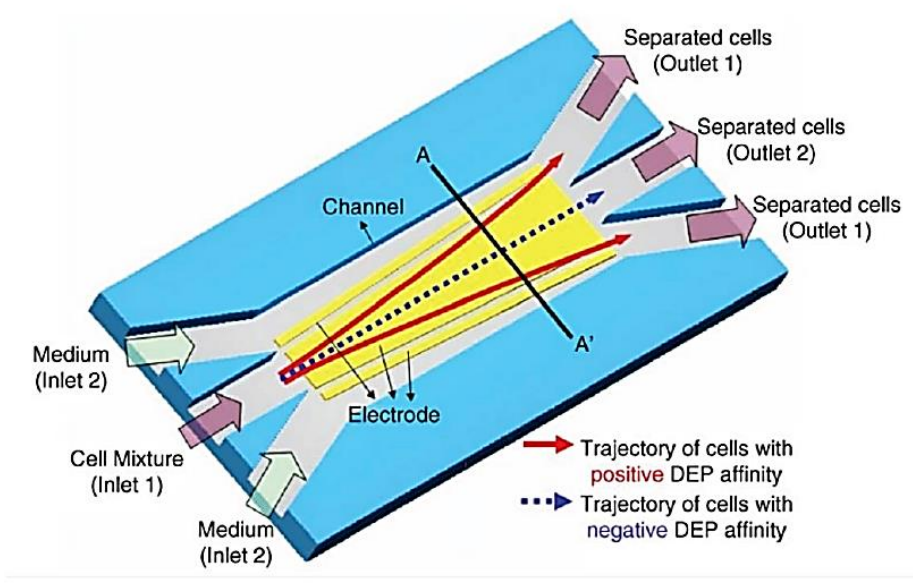

Figure 2-10: Overview of the designed microfluidic device to take advantage of the dielectrophoresis phenomenon [84]

Table 2-1: Advantages and disadvantages of separation under an electric field

\begin{tabular}{|c|c|}
\hline Benefits: & Limitations: \\
\hline Increasing accuracy, Precise control, Relatively \\
high-speed operation, Unchanged functional \\
state of the cells, Contactless & $\begin{array}{c}\text { Large sample needs larger electrodes, Not } \\
\text { suitable for rare cell capture, Limited stability, } \\
\text { Time-consuming, Demanding sophisticated } \\
\text { and expensive equipment, Not applicable on a } \\
\text { rotational platform, Medium throughput, No } \\
\text { fair resolution, The sample must be diluted } \\
\text { before the operation }\end{array}$ \\
\hline
\end{tabular}

\section{2-3-1-2- Acoustic Cell Sorting}

This section explains how acoustophoresis forces separate the CTCs from peripheral blood samples obtained from cancer patients through an acoustic-based microfluidic device. Acoustic devices operate based on the separation of particles exposed to the acoustic field and acoustic waves [92-94]. In this method, a stationary wave is formed inside the microchannel. A stationary wave is a wave whose fluctuation amplitude is a constant value at any specific point along the wave axis. The stationary wave occurs when two waves with similar frequency move in opposite directions of each other. The overlap of these two waves forms such a wave. A Pressure Node is formed at both ends of this stationary wave. The node in stationary waves refers to the points that are fixed.

In contrast, Pressure Antinode develops at some points. The Pressure Antinode in stationary waves refers to the points experiencing the greatest displacement. These waves originate from the 
difference in the particles' density and compressibility and the fluid's surrounding environment. Putting particles in such a fluid field creates waves affecting the particles and propelling them towards the pressure node and Pressure Antinode [95, 96]. Figure 2-11 depicts an overview of a microfluidic device separating particles from each other through stationary acoustic waves [73]. The set of these above factors leads to defining a parameter called the Contrast factor [32].

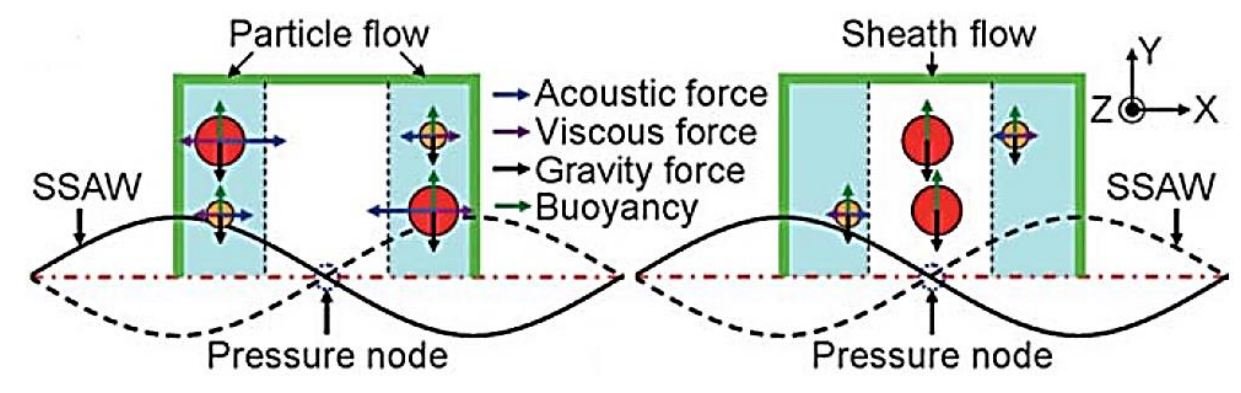

Figure 2-11: Overview of a microfluidic device that isolates particles from each other using standing acoustic waves [73]

In this method, red blood cells are employed to separate the fat particles forming and entering the blood through open-heart surgery. This method has also been used to separate the live and dead blood cells and concentrate on the population of live and healthy cells [97]. Peterson and his colleagues could apply this method to separate two and 10-micrometer particles and particles in the blood, such as platelets, red, and white blood cells [98].

When a fluid is exposed to ultrasonic waves' radiation, its temperature rises and may damage cells. Evander and his colleagues studied this temperature increase on neural stem cells and showed that cells could survive for about 15 minutes under a particular acoustic field [99]. In another study, Johansson et al. adopted this method to isolate cells in a flow cytometry microfluidic device [100]. Norris et al. applied this method to separate Sperm cells from Epithelial cells [101]. However, the facing challenge of using such a method is to choose the right material for making the device that can pass the acoustic wave through itself [102]. This method was proposed in 2014 by Massachusetts State University to isolate blood cancer cells from the others. The acoustic wave angle applied to the fluid flow was optimized, and its optimal value to maximize the number of separated cancer cells was achieved; Figure 2-12 shows a schematic diagram of such a method [103]. 


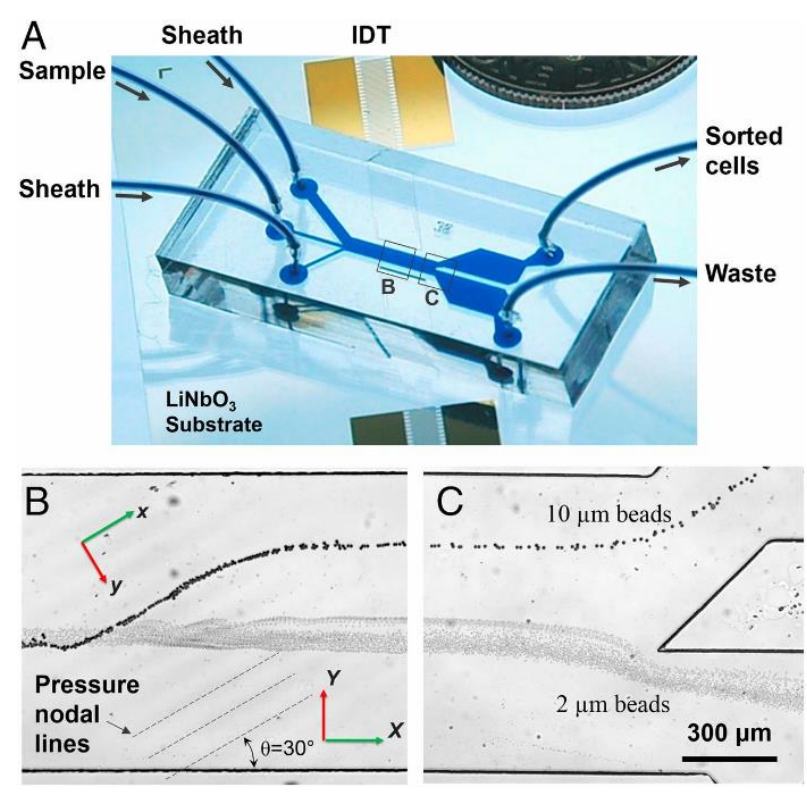

Figure 2-12: Cancer cell isolation device using acoustic waves [103]

In this method, two forces, including a drag force and the force applied to the cells through acoustic waves, are applied to the particles. Among these, cell mass, the angle of pressure lines owing to acoustic waves and fluid flow, the value of acoustic waves, and fluid mass flow rate play a significant role in cell separation. In this method, the number of pressure lines, unlike its traditional case, is more than one; therefore, if the target cell escapes from one of the pressure lines, it will be trapped into the next line. In the direction of the force applied by the pressure wave, the target cell starts moving along the direction of those lines. As a result, cancer cells are separated from the normal cells that do not move on those lines.

In this method, all parameters were optimized so that the optimal value for the pressure lines' angle was 30 degrees. Consequently, larger and smaller cells move in the direction of the pressure lines and the direction of the fluid flow, respectively; such a phenomenon causes the cells to separate from each other. According to experimental observations, CTCs exposed to the acoustic field have more mobility and activity than the other blood cells so that they are concentrated up to 1,000 times without affecting the primary function of the cell. Hence, the CTCs will be healthy and unchanged for subsequent studies (Figure 2-13) [104, 105]. In figure 2-13, a schematic of the experimental setup for acoustophoretic cell separation was shown. The sample was drawn from a test tube via a common side's inlet and laminated near the separation channel walls, while cell-free medium injected through the central inlet occupied the central part of the flow. Cells were subjected to ultrasound in the separation channel and moved toward the channel center at a rate determined by their acoustic 
properties and size. Two sample loops were used to collect cells from the sides and the outlet center, respectively.

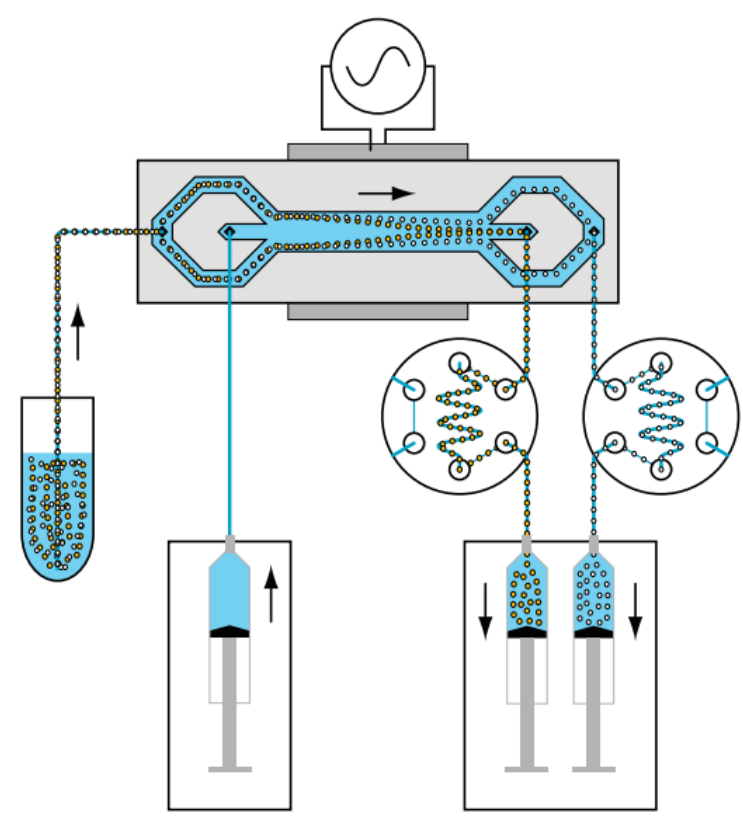

Figure 2-13: Overview of acoustophoretic separation, The solution containing CTC and white blood cells enters at the beginning of the channel pathway; another same solution without cells for conducting the cells towards the region that electric field applied enters at the channel center. As such, having applied the acoustic field, the white blood cells and CTCs are separated based on size and mobility [104]

Table 2-2: Advantages and disadvantages of separation under an acoustic field

\begin{tabular}{|c|c|}
\hline Benefits: & Limitations: \\
\hline $\begin{array}{c}\text { Contact-free sorting, Noninvasive, Good } \\
\text { penetrability, Gentle on cells }\end{array}$ & $\begin{array}{c}\text { Technical constraints, insufficient throughput, } \\
\text { lack of long-term device stability, need for a } \\
\text { piezoelectric substrate for chip fabrication }\end{array}$ \\
\hline
\end{tabular}

\section{2-3-1-3- Magnetic Activated Cell Sorting (MACS)}

Since the separation process principles in microfluidic devices are similar to non-microfluidic devices, the fundamental issues and principles of separation by applying a magnetic field were expressed in the non-microfluidic device section. Due to the importance of the magnetic field separation method, numerous studies and improvements have been made. Actually, the magnetic 
separation devices have been considered in the micro dimension to increase the accuracy and reduce the required sample volume for isolation [75-78].

All the already mentioned active methods have been without the usage of antibodies. However, in this method, the specific antibody for the cancer cells firstly has to be attached to the surface of the magnetic particles (so-called magnetic beads made of nano-metric-sized iron oxide particles, such as magnetite $\left(\mathrm{Fe}_{3} \mathrm{O}_{4}\right)$, encapsulated or glued together with polymers; providing super-paramagnetic properties, ranging from $35 \mathrm{~nm}$ up to $4.5 \mu \mathrm{m}$ ) and then entered into the bloodstream to cover the cancer cell antigen surface; this is how the cancer cells accept the magnetic property. Subsequently, while the blood with labeled CTCs crosses through a microchannel affected by the magnetic field, the desired cancer cells are isolated and attracted to the magnetic plates [106]. As shown in figure 2-14, if the applied force to the cancer cells with magnetic properties is large enough, it will be absorbed by the plate and separated from the healthy blood cells exiting the outlet.

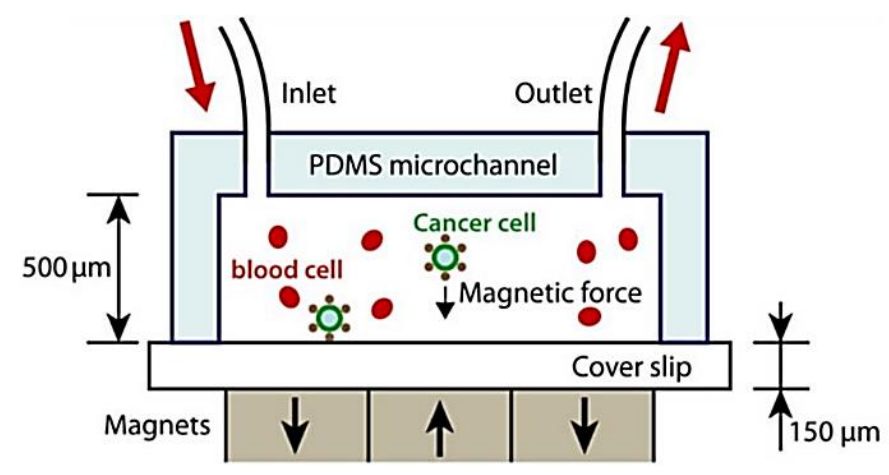

Figure 2-14: Isolation of cancer cells using antibodies

Separation of cells by catching them inside a tiny volume of the droplets (cell-containing microdroplets), one of the oldest cell isolation methods, has been improved by integration with the magnetophoretic method. A uniform magnetic nanoparticle (MNP) solution and cell-containing microdroplet method have been used to separate microalgae in similar research. According to anticipation, similar amounts of nanoparticles will enter in droplets with a similar size, but due to the occupied volume by the algae, smaller numbers of them will settle in droplets containing algae. The same-sized droplets containing roughly equal amounts of MNPs show the same degree of magnetization under the constant magnetic field. However, the number of MNPs inside the droplets containing single cells is reduced by the single cell's volume, resulting in low magnetization. In other words, droplets containing algae, a smaller amount of particles will be entered because of algae's occupied volume. As a result, droplets carrying algae have weaker magnetic properties than others. The reduced number of MNPs by the occupation of a single cell in a droplet caused a lower magnetic 
force than the droplets without single cells, resulting in a difference in droplets' lateral positions. Finally, the separation takes place by applying the magnetic field [107].

It should be noted that separation by the magnetic field is more efficient than conventional methods such as flow cytometry so that 80 to $90 \%$ of cancer cells among up to $10^{11}$ cells can be isolated in about 30 minutes [108]. One of the main advantages of working with this method is not damaging body cells and tissues. Generally, the suitable permeability of the body cells exposed to the magnetic field helps them avoid being hurt [109]. Another advantage is the ability to separate large numbers of cancer cells during one step.

Moreover, only the magnetic field can be employed on the rotational platform such as the lab on a CD (LOCD). For active separation methods, the most critical obstacle is applying the active techniques on a rotational disk. For example, In Acoustophoresis and Dielectrophoresis separation methods, we need an electric source to supply sufficient power for generating the acoustic waves or electric field. The generators must always be attached to the power supply. Due to this connection, it is impossible to spin the platform on which operators and the microfluidic system are settled. While the magnetic field will only need an inserted magnet on the rotational substrate, the target cells must hold magnetic properties to react in the magnetic field's presence. The problem is that these nanoparticles cannot be directly attached to CTCs; they must be first connected to the specific antibody of the cancer cells. The antibody can then connect to the mentioned cell's antigen (an interaction similar to a lock and its corresponding key). After such a connection, the generated force drives cancer cells towards a magnetic source. If this force is large enough, the cancer cells will be deviated and separated from other healthy blood cells.

Therefore, the coupling of antibody and nanoparticles and their combination with the cancer cell antigen represents a vital role in the successful separation of CTCs and the employed active method. As the antibody binding to these nanoparticles and then to the cancer cell antigen increases, the separation rate under the applied magnetic field will also be significant; because more particles can obtain magnetic characteristics. Consequently, the isolator should offer another opportunity for achieving the suitable mixing in the shortest possible time to nanoparticles that have failed to bind or combine with antibodies.

However, there are some disadvantages as well; for example, although the results have shown that this method does not hurt healthy body cells and tissues, the cancer cells will probably die due to the loaded stresses on them. This issue eliminates the possibility of further investigation of CTCs. Therefore, Ingber and his colleagues proposed another separation method to resolve this problem. 
Their device consists of one main microchannel and several perpendicular chambers to the primary microchannel [106]. As shown in figure 2-15, the magnets installed adjacent to the chamber force the cancer cells to enter the chamber. Therefore, the stress on the cancer cells in the chambers will be minimized, and the cells remain alive.

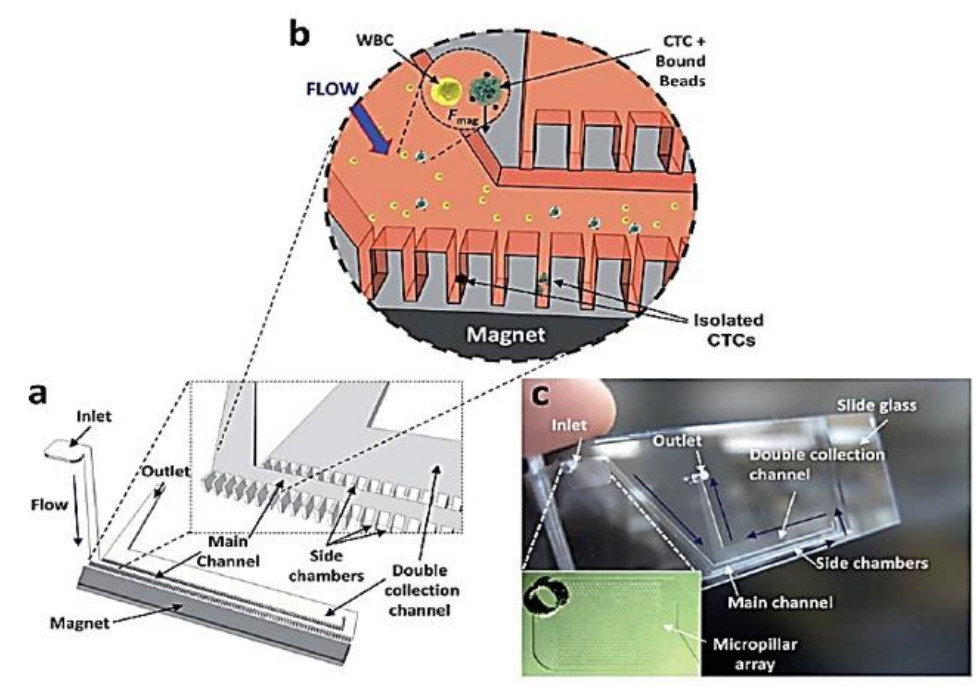

Figure 2-15: Stress reduction by inserting multiple chambers

Subsequently, when the blood flow transits through the channel, the magnetic cancer cells are trapped inside the chambers and separated from the mainstream. Another problem is that cells with less than $1 \%$ frequencies cannot be isolated through this method. Besides, cell separation is highly dependent on the process of cells being covered by magnetic beads, which is a time-consuming process [89].

As mentioned before, due to the cancer cells' low magnetic permeability, they must be marked with magnetic nanoparticles (consisting of iron oxide particles) before usage of the magnetic field for separation. However, there are two significant problems; first, the conventional methods for mixing nanoparticle and cells are time-consuming. Most of the time, they suffer from good throughput; therefore, a better geometry to mix them sufficiently is required. Second, CTCs cannot directly attach to magnetic nanoparticles. In fact, the specific antibody for the cancer cells firstly has to be attached to the surface of the magnetic nanoparticles. Next, they must cover the CTC surface; this is how the cancer cells exhibit magnetic behavior in the presence of an external magnetic field. Subsequently, these labeled CTCs are separated from the healthy blood cells and absorbed by the magnetic plates.

Practicing a uniform magnetic field to separate cells without the usage of micro-beads is also feasible. Unlike the previous method in which the magnetic antibody tags cells, the cells are separated by their 
different magnetic characteristics in this new approach. Han and his colleagues used this method to detach red and white blood cells from each other (Figure 2-16) [110].
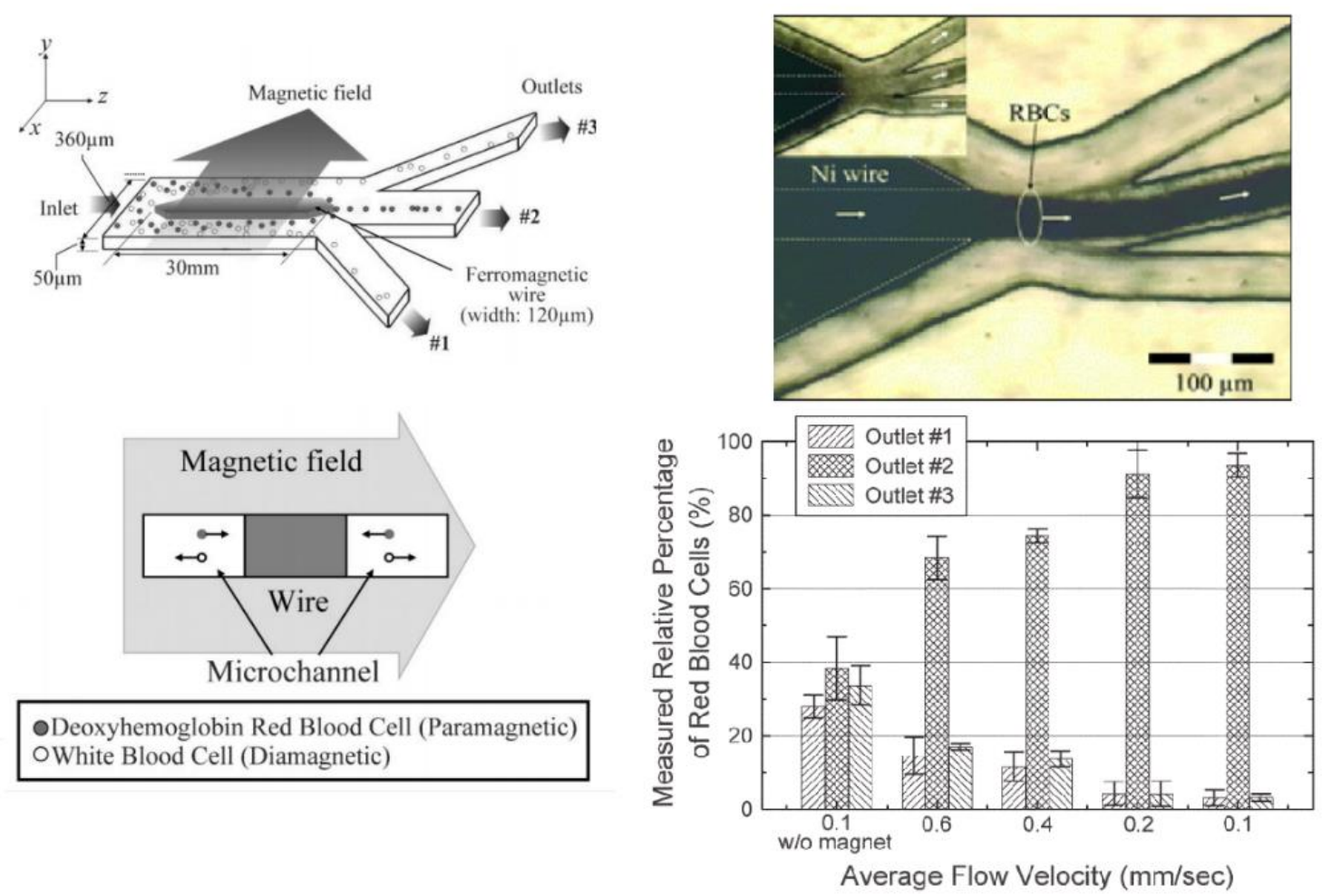

-Deoxyhemoglobin Red Blood Cell (Paramagnetic) OWhite Blood Cell (Diamagnetic)

Figure 2-16: Overview of a microfluidic device separating red and white blood cells utilizing magnetic properties [110]

White blood and red blood cells have diamagnetic and paramagnetic attributes, respectively. Siegrist reported successful and highly purified separation and capture of breast cancer cells (MCF7) from HeLa cells using a magnetic field in the centrifugal microfluidic system (so-called CentrifugoMagnetophoretic Platform) constituted by the stable hydrodynamic fluid as the isolation platform [111]. During this research, breast cancer cells were attached to magnetic particles using a particular antibody (anti-EpCAM). Subsequently, Kirby [112, 113] and Glynn [114] developed the above primary scheme. They optimized the microfluidic centrifugal system to separate the magnetic particles from the non-magnetic ones, detach the cancer cells from the blood sample, and remove the circulating and undesirable magnetic particles from the outlet flow (Figure 2-17). 


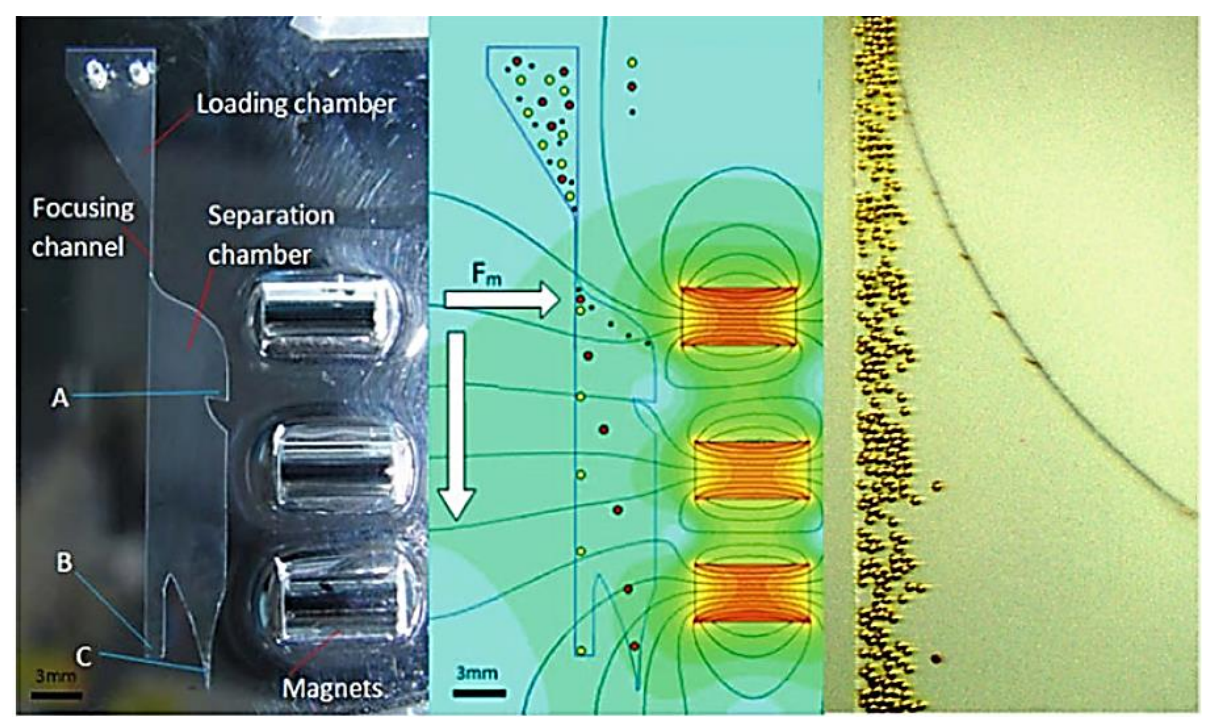

Figure 2-17: Schematic overview of the centrifugal magnetic separator with a stable fluid platform [112]

The most critical drawback of centrifugal designs is that it is difficult to directly separate CTCs from the patient blood sample due to the low and limited sample volume. Although using an initial-fixedsubstrate separator at the outside of the device has been suggested to eliminate this problem and concentrate the target cells, transferring the sample from the first to the second separator is timeconsuming sensitive and makes it probably contaminated. Also, because of the flow control system's lack of stable platform separators, the necessity has always been to control the fluid flow, not by applying another external field! Centrifugal microfluidics takes advantage of not using the mechanically external equipment for regulating the fluid flow. If these two separators are implemented simultaneously on one plate, significant progress will achieve in this field. Nevertheless, the complexity of this idea has discouraged researchers from pursuing it.

Table 2-3: Advantages and disadvantages of separation under a magnetic field

\begin{tabular}{|c|c|}
\hline Benefits: & Limitations: \\
\hline $\begin{array}{c}\text { High accuracy, Low sample volume, A } \\
\text { promising tool for single-cell analysis, } \\
\text { Effectiveness and convenience, Simple and } \\
\text { easy to manipulate, Fast processing, Suitable } \\
\text { for breast cancer cells }\end{array}$ & $\begin{array}{c}\text { High dependent of magnetic field gradient, } \\
\text { magnetic nanoparticle concentration, and } \\
\text { magnet position; Too dependent on mixing } \\
\text { cells and magnetic beads, Need an initial step } \\
\text { to enrich the target cells, Risk of contamination } \\
\text { in case of using initial step, Increasing the } \\
\text { concentration of unwanted by-products, } \\
\text { Requiring careful adjustment of flow rates }\end{array}$ \\
\hline
\end{tabular}




\section{2-3-2- Passive methods of cell separation}

Despite active methods, no external force is regarded for passive ways to separate the particles. In this type, the adopted mechanism is geometry and nonlinear hydrodynamic forces. Since hydrodynamic forces are the main forces employed in these devices to separate particles, these devices are also known as hydrodynamic separation techniques. The main idea behind passive methods is that cancer cells are typically larger than other blood cells, such as red and white blood cells, and have higher surface tension. These physical differences in size [115, 116], density [74], and formability [117] assist scientists in devising different passive methods reviewed below for isolating CTCs from the blood. Pinch Flow Fraction (PFF) [118-125], hydrodynamic filtration [126-128], and Deterministic Lateral Displacement (DLD) [32, 48, 52, 92, 129-135], bifurcation, and inertial microfluidic are examples of passive devices that can be pointed out.

Since there is no ability to precisely control operations over time, such devices' separation proficiency and accuracy are usually lower than the active models. However, their advantage over active devices is the high-speed operation due to entering the sample's greater introduced flow rate to the device. In addition, the device fabrication process is much easier because of no requirement of external power fields; therefore, the total cost of construction is much low.

\section{2-3-2-1- Blood cell separation devices using microfilters}

The basis of separation, with the help of a filter, was described in non-microfluidic devices. The development and standardization of micro-fabrication protocols have contributed significantly to the filtration process because they allow for exact control of the channel geometry, a high resolution, and high reproducibility of the design. Since pores size and geometry are precisely controlled by microfabrication, microfluidic devices recover tumor cells with higher efficiency via filtration.

Since filters have various structures, they are categorized into weir-type, pillars, cross-flow, and membrane [32]. This process has been done to separate white blood cells from the whole blood, extract DNA, and study its properties. This process, considering the size and deformability of white globule, is performed by various types of Silicon-based filters so that it has resulted in longer filter life and no damage to the cells (Figure 2-18) [136]. 


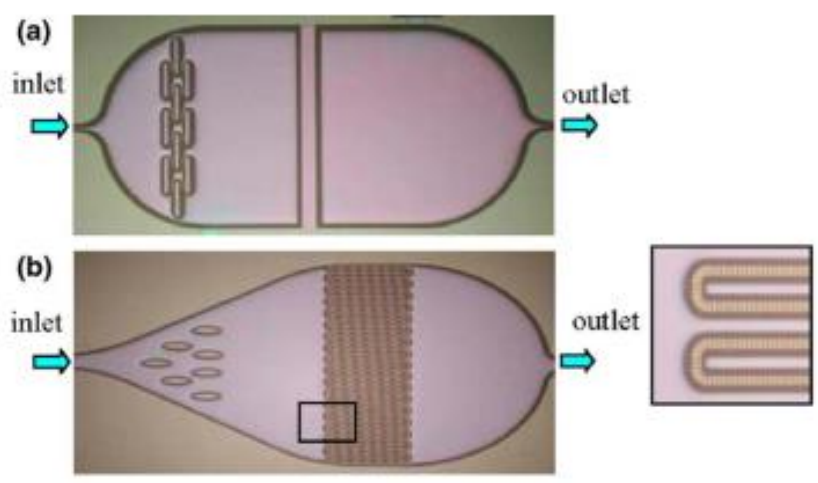

(c)

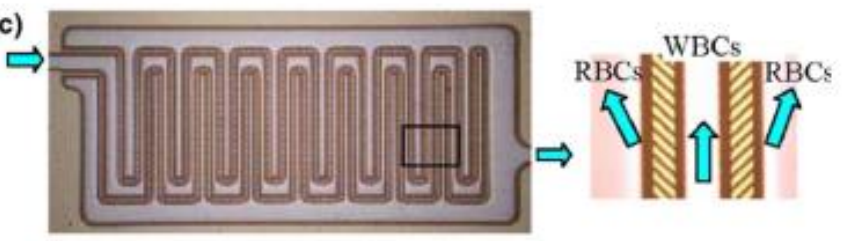

(d)
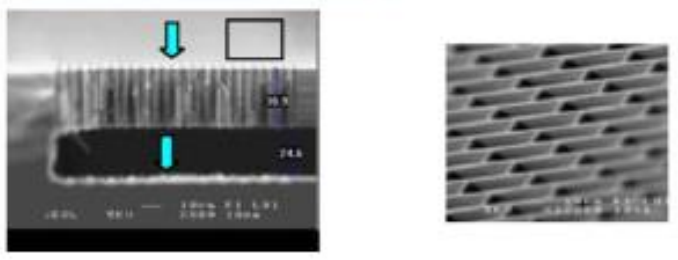

Figure 2-18: Different types of usable silicon filters to separate white blood cells: a)weir-type, b)pillar, c)cross-flow, d)membrane [136]

Besides, Plasma separation from blood to investigate its properties and extract proteins without damaging the plasma or blood cell part is one of the most common studies in the filter fabrication $[137,138]$. However, the application of this process to isolate cancer cells goes back to 2013. Lin and colleagues developed a method in that year to detach cancer cells by taking advantage of differences in cells' surface tension [139]. In this method, as shown in Figure 2-19, the fluid enters an area with embedded obstacles when it passes through a microchannel. 


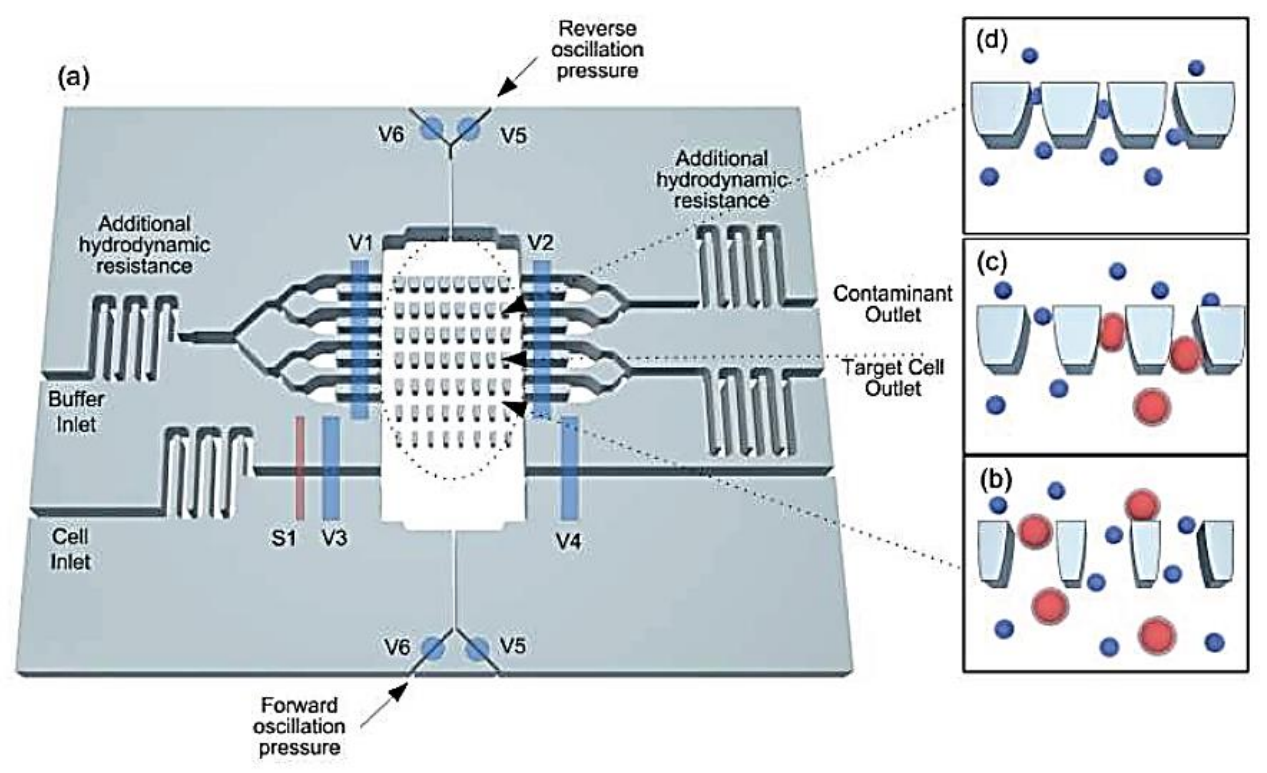

Figure 2-19: Separation due to surface tension differences

Because of cells' deformability, they will move through these obstacles if the necessary force is applied. The amount of required force for driving cells through barriers depends on the surface tension amount; meanwhile, since cancer cells have more surface tension, they need more pressure to pass through. If the applied pressure difference between the two points of the upper and lower of V5 is chosen to such an extent that the cancer cells cannot pass through the barriers while the other cells can. The cancer ones have been trapped in among one of these rows of barriers and are then separated.

\section{2-3-2-2- Bifurcation}

This method's principle is the separation of the blood cells at a bifurcating region of the capillaries and is supported by the Zweifach-Fung effect (Bifurcation law). This effect was first observed by comparing blood flow in capillaries and blood veins. The Zweifach - Fung effect indicates that when red blood cells move through a bifurcating region of a capillary blood vessel, they tend to enter the daughter vessel having a higher flow rate. They choose the daughter vessel because they will be subjected to higher gradient pressure; contrarily, few cells travel into the lower flow rate vessel.

Having followed the random motion of the red blood cells at a bifurcating region of capillary blood vessels, scientists observed that such cells have a tendency to choose paths with higher pressure gradients and greater flow rates. This is true for capillaries whose dimension is equal to or smaller 
than the red blood cells $[140,141]$. These cells' separated movement has been reported in the mentioned capillaries by comparing white and red blood cells. Because of the smaller dimension, the red blood cells move faster than the white blood cells. In the upstream of the white blood cells, there is a region with a high density of red blood cells; while in their downstream, a region free of red blood cells can be seen [142]. Numerous devices inspired by this manner of the blood flow inside the body have been devised to separate the blood particles. One of such devices' most outstanding applications is the continuous separation of blood cells from the plasma (Figure 2-20) [143-145].
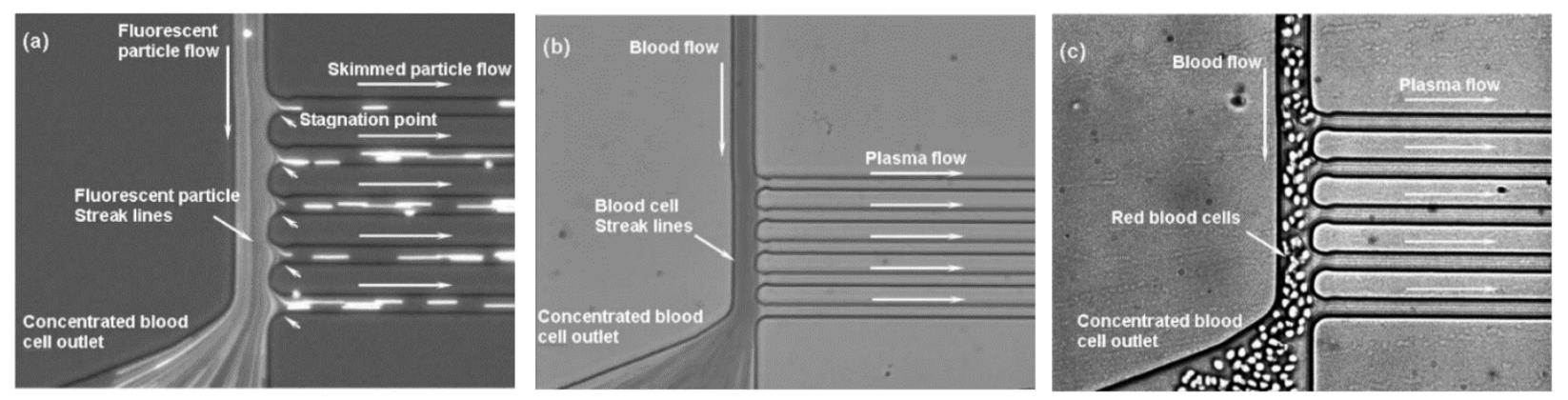

Figure 2-20: Blood plasma separator using the bifurcation law [144]

Herringbone structure is known as another manufactured device, which is a subset of the bifurcation concept. In this device, the channel is designed as branches alternately opposite directions to the left and right. The arrangement of the fish bones inspires the nomination of the herringbone structure for this geometry design. This method was initially proposed for centralizing particles. Accidental and irregular movement of the flow because of the continuous changes in the direction creates helical flow and a large number of vortices. Such a movement ultimately leads to a better concentration of the particles [146]. The herringbone structure is also employed to separate the CTCs in channels whose surfaces are coated with antibodies. Several direction changes in these structures cause the mixing between cells and antibodies to enhance (Figure 2-21) [147]. Modeling and simulation of this structure have also been executed to improve the geometry and achieve higher yields. 

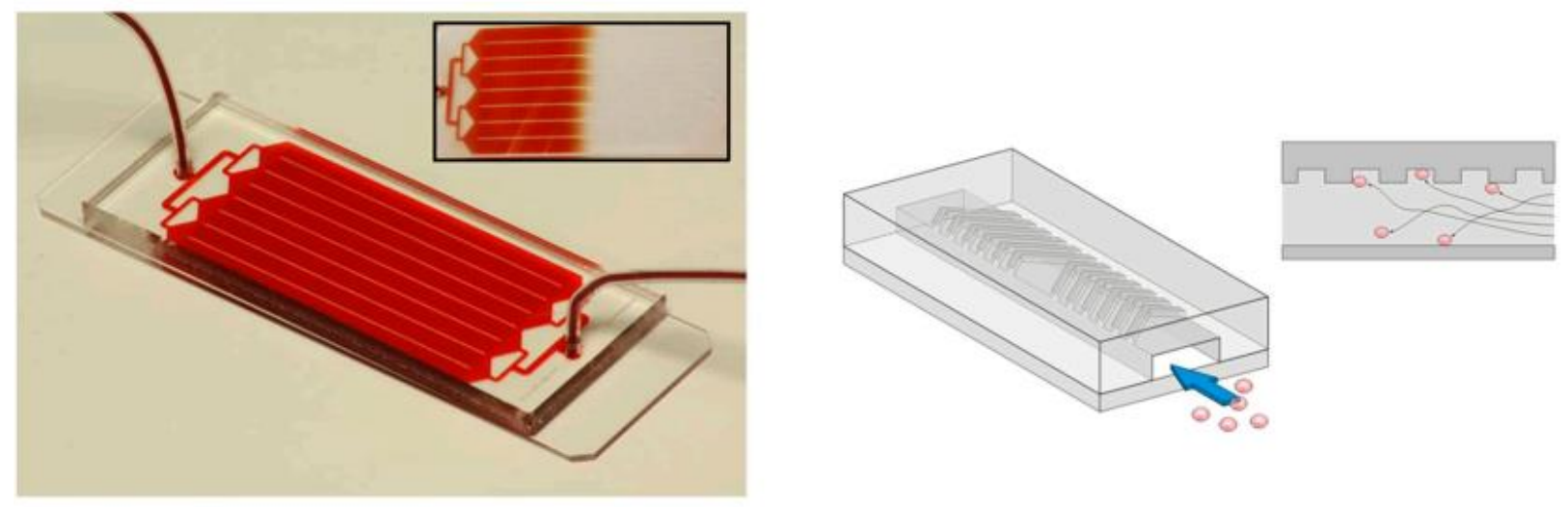

Figure 2-21: Herringbone pattern-based device for isolating CTCs [147]

Although many researchers have already carried out the simulation and numerical modeling of this phenomenon and their results have been evaluated along with experimental achievements [148, 149], this method has not been used independently and directly to separate CTCs from the blood yet. According to the physical characteristics of CTCs and how the blood cells move, it has been integrated with other methods to separate these cancer cells $[150,151]$.

Table 2-4: Advantages and disadvantages of separation by Zweifach-Fung effect (Bifurcation law)

\begin{tabular}{|c|c|}
\hline Benefits: & Limitations: \\
\hline $\begin{array}{c}\text { Increasing the total throughput, No external } \\
\text { power source, Time and cost-efficient, } \\
\text { Concentrating particles, Enhancing mixing } \\
\text { performance, Reducing the diffusion length, } \\
\text { Increasing the interfacial area of fluid }\end{array}$ & $\begin{array}{c}\text { Cannot be used alone, Geometrical constraint, } \\
\text { Better performance in mixing than separation, } \\
\text { Only work well under specific flow rates and } \\
\text { cell concentrations, Require external } \\
\text { controller, Can be harmful to cells, Time- } \\
\text { consuming }\end{array}$ \\
\hline
\end{tabular}

\section{2-3-2-3- Pinch Flow Fraction (PFF)}

Pinched Flow Fractionation (PFF), known as a relatively simple way, was first considered for particle separation. Its mechanism is the separation based on the size and density of the particles. In other words, this method utilizes the mechanism that the particles follow the streamlines in laminar flows, which is one of the characteristics of this flow regime [152].

As illustrated in figure 2-22, two inputs are considered in such a device; one is for the fluid containing particles; another is allocated for a particle-free fluid having a diluent role. Firstly, the liquids, 
including particles and diluents, are continuously entered into the microchannel with a particular geometry from each introduced inlet. At this time, the liquid flow containing particles is focused on one sidewall in the pinched segment by controlling flow rates from both inlets. The fluid provides the necessary force to control particles without particle.

There is a pinched segment in the middle of the channel that connects the inlet to the wide outlet (Figure 2-22) [119]. As seen in the pinched microchannel segment of Figure 2-22, the particles, regardless of their size, are conducted toward a wall and move parallel to this wall. In that segment, the particles are concentrated near the upper wall using two-fluid flow control.

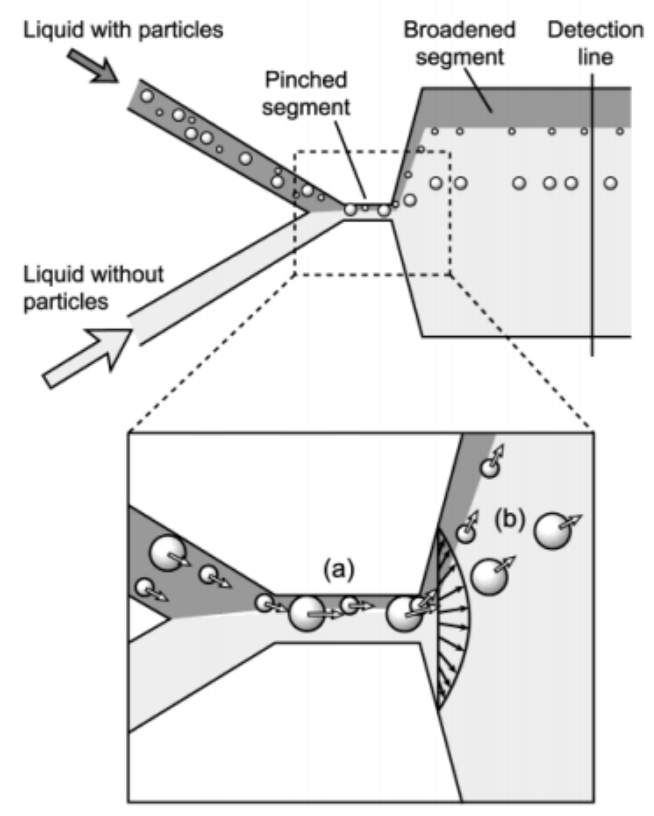

Figure 2-22: Schematic of the PFF method, Particle-containing and particle-free fluids are introduced, a) In the pinched segment, all particles are directed towards the wall. b) In the wide part, the particles are separated according to size in the direction perpendicular to the flow [119]

In laminar flows, particles tend to travel along the streamline that passes through their center of mass. This streamline is near the top wall for smaller particles, while larger particles move farther away from the top wall and closer to the microchannel center. Finally, the particles are separated in the perpendicular direction to the flow, based on differences in their sizes and particle profiles' distribution, when they exit the narrow microchannel segment. According to the used mechanism in separation, two fluids' flow is considered incompressible and laminar in this method. Besides, different types of particles can be separated through this method. 
The main advantage of such a method is that the particle concentration can slightly influence the separation efficiency [123]. The size of the isolated particles depends on the inlet two flows' rate. Moreover, the separation efficiency depends more on the design of the microchannel contraction part through which the fluid passes.

If the microchannel width in the pinched segment is larger than a certain amount, flows containing particles will not have a suitable distance from each other when leaving this section. At the beginning of using this separation method, the pinched and broadened segments' width was introduced as the only determinant of separation [119]. According to the particle size, Yamada et al. have proposed an experimental relation (Relation 1-2) for designing the microchannel pinched segment width [119].

$$
y_{0}=\left(w_{p}-\frac{D}{2}\right) \frac{w_{o}}{w_{p}} \quad(1-2)
$$

In the above relation, $w_{o}$ is the microchannel width at the output, $w_{p}$ is the microchannel width at the pinched segment, $\mathrm{D}$ is the particle diameter, $y_{0}$ indicates the distance between the center of the particle's mass and the microchannel center at the output. The physics of the subject was examined in more detail in later articles [153]. However, in subsequent studies, it was found that the microchannel aspect ratio, particle size difference, and the microchannel sidewall roughness affect the separation so that particles with diameters on the order of the sidewall roughness cannot be separated employing pinched flow fractionation [120]. Figure 2-23 shows that the outlet channels are symmetrically established relative to the microchannel contraction region [124].
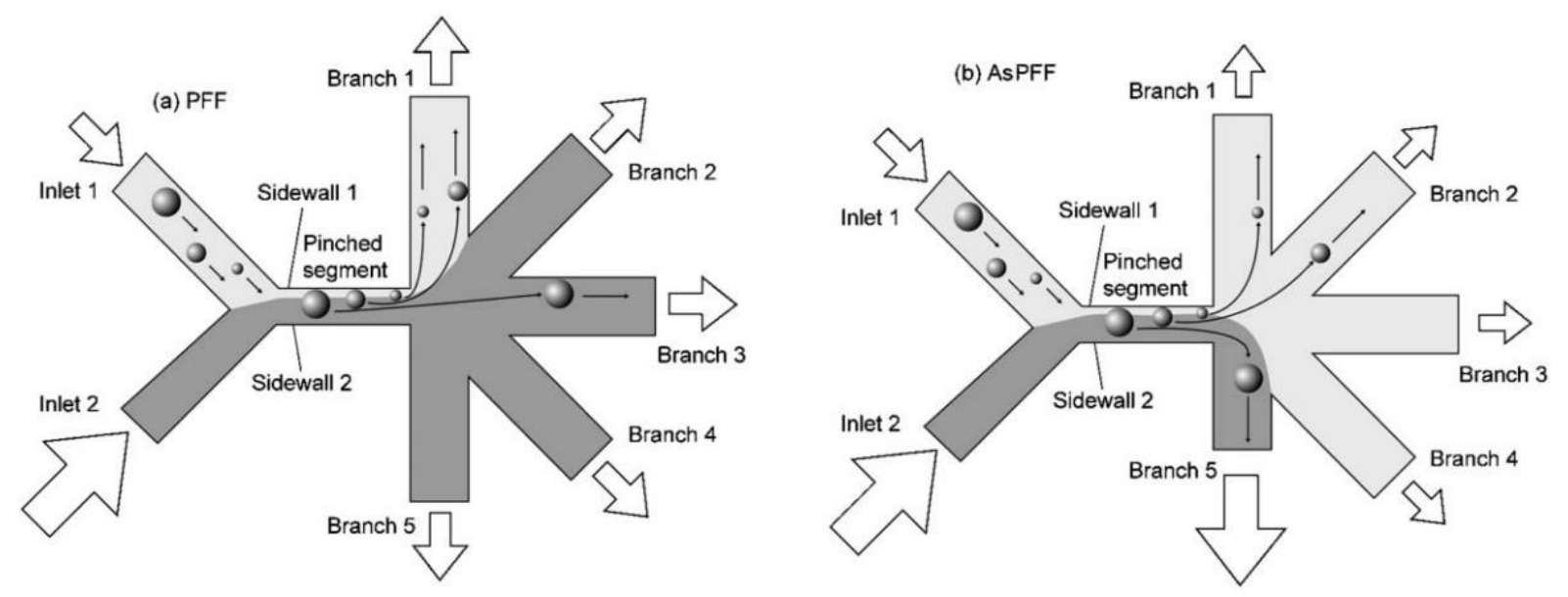

Figure 2-23: Overview of the particle path in a microfluidic device using the Pinch Flow Fraction 
Therefore, the fluid travels with a similar flow rate in the microchannel outlets. Large particles continue their straight movement and depart through the outlet located in the center. However, according to the streamline on which they are located, smaller particles leave through the upper microchannels. As a result, the microchannel outlets, which are lower than the pinched segment, separate fewer particles. In the Asymmetric Pinch Flow Fraction (AsPFF) method, the microchannel outputs are asymmetrically placed to enjoy better efficiency. In this innovative method, one outlet is designed with more width or less length to get more fluid out of this microchannel [124]. This channel is usually placed along the pinched microchannel, and the flow rate of the two fluids is adjusted so that no particle comes out of this output. In this way, all microchannels are used efficiently. (Figure 2-24)
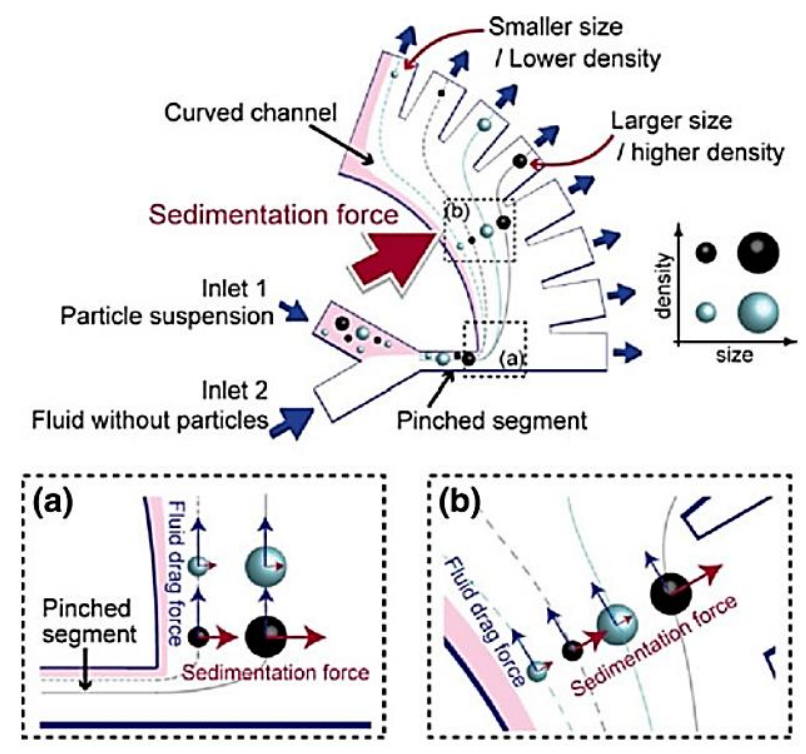

Figure 2-24: Overview of the microfluidic device using Asymmetric Pinch Flow Fraction separation method [125]

Another significant benefit of this separation method is its ability to separate droplets with different sizes, while centrifugation and filtration methods cannot detach such droplets [154]. Curving the microchannel or rotating the device can remarkably improve this separation method [125]. In the first technique (i.e., curving the microchannel), the pinched channel's end section ends in a curved microchannel with a small radius (Figure 2-25) [125]. 


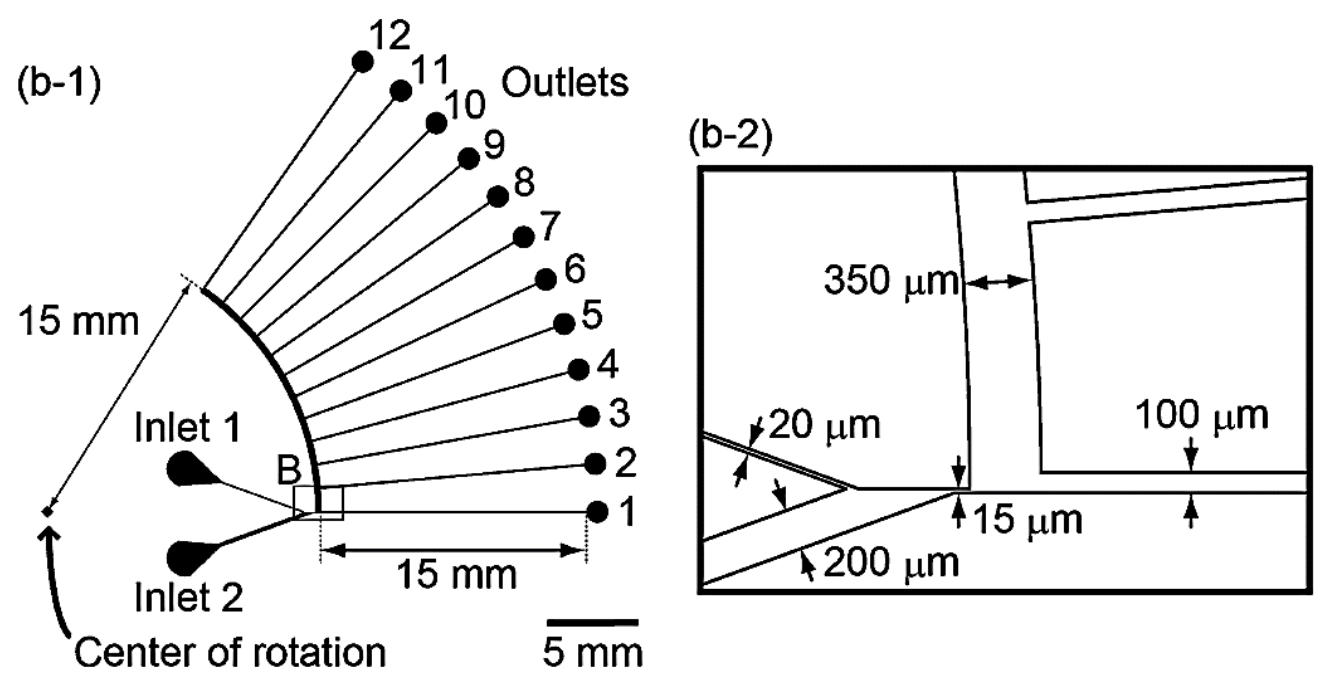

Figure 2-25: Overview of a microfluidic separator using the Pinch Flow Fraction method and curved microchannel [125]

According to the size and density, when the particles enter the curve-shaped channel, the inertial force gives them a velocity in the perpendicular direction to the fluid motion. As a result, this novel technique can separate particles with the same radius but different densities. Particles with equal size but higher density are trapped in more primitive outputs. Particle sedimentation velocity $\left(U_{s}\right)$ is given in Equation 2-2 [125]:

$$
U_{s}=\frac{\rho_{p}}{18 \mu r_{c}} D_{p}^{2} U^{2} \quad(2-2)
$$

In the above relation, $\mu$ particle density, $\rho_{p}$ is the fluid's dynamic viscosity, $r_{c}$ is the curve's radius, $D_{p}$ and $U$ are the particle diameter and the average fluid velocity, respectively. In the above equation, the sedimentation velocity is directly proportional to the average fluid velocity square. The lower the average fluid velocity in the microchannel, the closer this method is to the primary Pinch Flow Fraction separation method; moreover, the inertial force (towards the center) becomes negligible. In the second method (rotating the device), the microfluidic device rotates at a speed of several hundred revolutions per minute (Figure 2-26). 
(a-1)
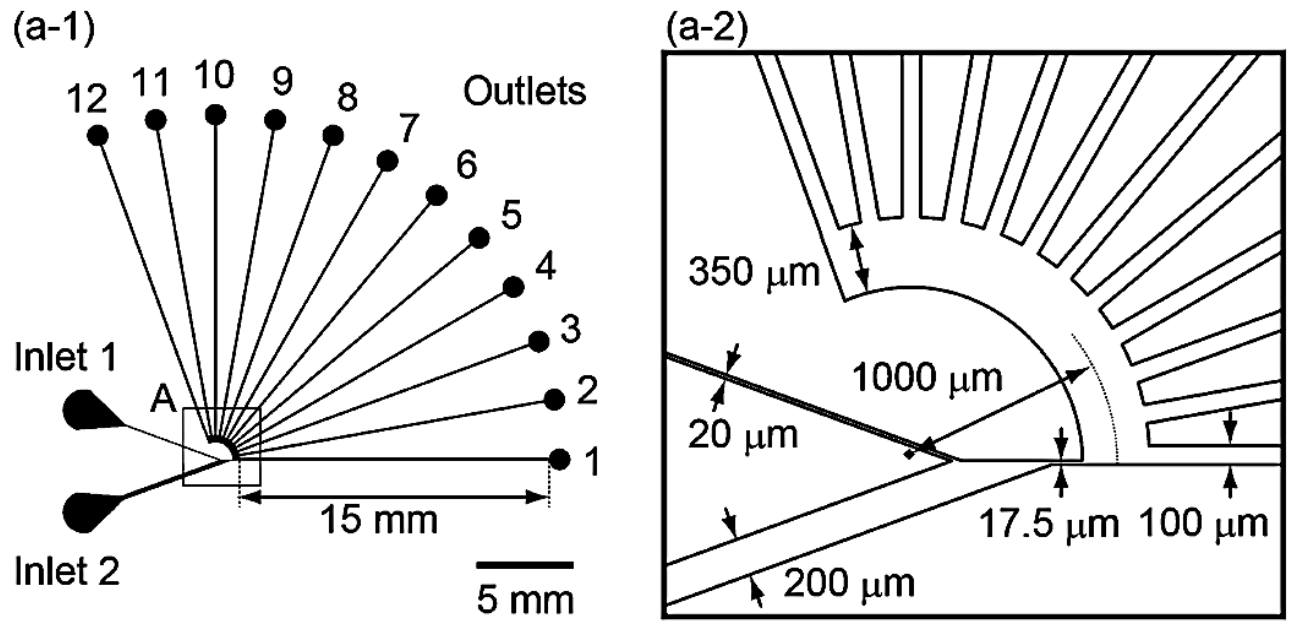

Figure 2-26: Overview of the microfluidic separation device using the Pinch Flow Fraction method and device rotation [125]

Consequently, the particle's sedimentation velocity, which is perpendicular to the fluid flow, becomes a function of the inertia due to the curve-shaped microchannel and the virtual centrifugal force on the fluid. Particle's sedimentation velocity can be obtained from Equation 3-2:

$$
U_{s}^{t}=U_{s}+U_{c}=\frac{\rho_{p}}{18 \mu r_{c}} D_{p}^{2} U^{2}+\left(\frac{\rho_{p}}{18 \mu}-\frac{\rho_{f}}{18 \mu}\right) D_{p}^{2} r_{d} \omega^{2}
$$

In the above relation, $U_{c}$ is the particle velocity due to the virtual centrifugal force, $r_{d}$ is the distance from the particle to the center of rotation, and $\mathrm{w}$ indicates the microfluidic device's rotational velocity. Morijiri et al. repeated this method with different rotational velocities. They found that the device's rotational speed did not significantly affect particle separation, and such a rotation could be more used as a pump [125]. By optimizing geometry based on this method (PFF), it also can isolate white blood cells from the whole blood [121]. Park et al. proposed another study using the same mechanism to separate CTCs in 2009 [122]. Figure 2-27 depicts a schematic of this method. 


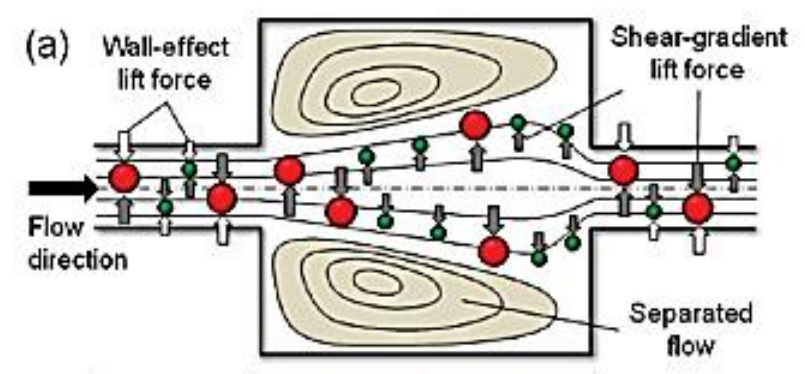

(b)
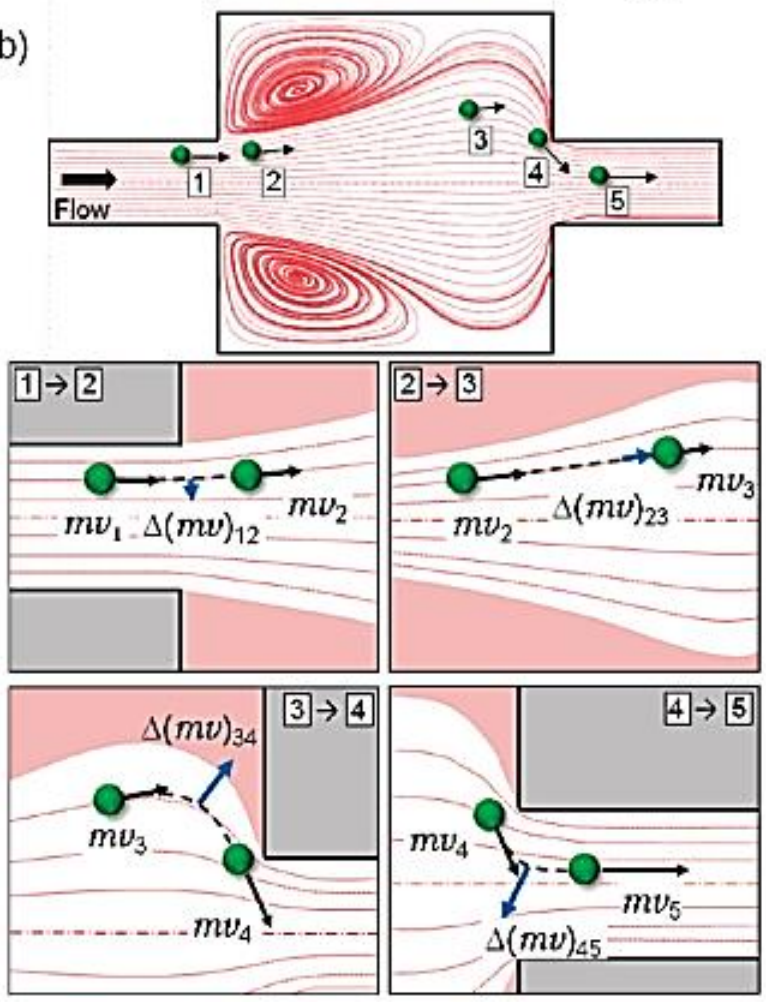

Figure 2-27: Microchannels with sudden expansions [122]

In this method, the fluid enters a microchannel, in which its cross-sectional area suddenly increases with certain distances. As can be seen in Figure 2-27, the fluid or blood streamlines change under such circumstances. If the particle completely follows the streamlines, it is trapped inside the microchannel's expanded section and starts spinning around itself. On the other hand, if the particle does not track the streamlines, it continues its path and does not enter the expanded area.

In this case, Stokes number is defined and states that particles with higher Stokes numbers do not follow the streamlines and continue their path. Cancer cells have a high Stokes number in the bloodstream; in other words, cancer cells are much more inert than the other blood cells due to their larger size, so the fluid flow cannot force them into the expansion section. As a result, red and white 
blood cells are trapped inside the microchannel through this method, and the cancer cells exit through the microchannel outlet and separated from the other blood particles.

However, one of the most undesirable drawbacks of using the PFF method is its fabrication difficulty. For the PFF method, a very narrow width (nearly less than $3 \mu \mathrm{m}$ ) of the channel in the throat area is the most significant geometrical features in separating target cells from a heterogeneous mixture. Due to the available common fabrication methods, creating such a channel with appropriate dimensions does not exist for all researchers.

Table 2-5: Advantages and disadvantages of separation by Pinch Flow Fraction method

\begin{tabular}{|c|c|}
\hline \multicolumn{1}{|c|}{ Benefits: } & Limitations: \\
\hline \multirow{3}{*}{ Simple mechanism } & $\begin{array}{c}\text { Not applicable for particles with diameters on } \\
\text { the order of the sidewall roughness, Sensitivity } \\
\text { to size, Time-consuming, Difficult fabrication } \\
\text { process, Required devices for injecting a small } \\
\text { number of particles into the separation field }\end{array}$ \\
\hline
\end{tabular}

\section{2-3-2-4- Deterministic Lateral Displacement (DLD)}

This approach relies on Detrimental lateral displacement (DLD). When a particle is injected into a low-Reynolds-number flow, it will have a deterministic behavior and follow that streamline, superposed with its intrinsic Brownian motion. In simple terms, particles in very viscous streams are trapped in the streamline and move along that streamline. The Detrimental lateral displacement (DLD) method consists of a microchannel with several transversely placed obstacles inside that channel. By inserting an obstacle in this particle's course, the particle's behavior in the mentioned flow will change. The DLD method applies the asymmetric bifurcation of laminar flow around obstacles for particle separation. Particles in solution are usually separated according to their size by exclusion or hydrodynamic Chromatography. Therefore, a particle chooses its path deterministically based on its size so that a critical size for the particle is initially defined in this approach. Particles smaller than the critical size will follow the main streamline around the obstacle without displacement perpendicular to the streamline so that their movement pattern will not be changed because of obstacles. On the other hand, when the particle is bigger than the critical size, it will collide with the obstacle and continue its movement in a new direction. This lateral displacement is responsible for this streamline switch. (Figure 2-28) 


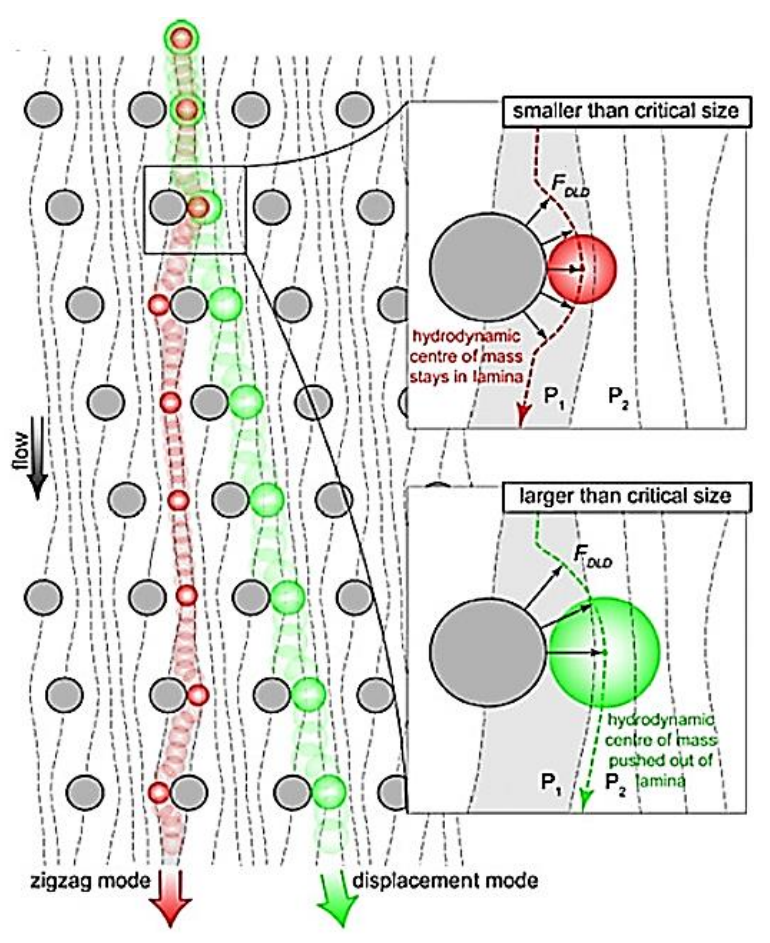

Figure 2-28: Overview of particle separation using the detrimental lateral displacement method [135]

This novel method was firstly used by Huang et al. to separate particles with diameters of $0.8,0.9$, and $1 \mu \mathrm{m}$ [129]. Changing the size of obstacles, the gap between them, and the arrangement of barriers will optimize such a separation [129]. Many biological subjects, such as the isolation of nucleated red blood cells (NRBCs) from pregnant women's peripheral blood [130] and the separation of cells from the whole blood without any pre-processing, use this method [131]. This method was first performed to isolate CTCs by Dr. Tuner's research team at the Massachusetts Institute of Technology (MIT) university in 2007 [132]. The CTC-chip device was tested to separate cancer cells in patients with lung cancer (Figure 2-29). 


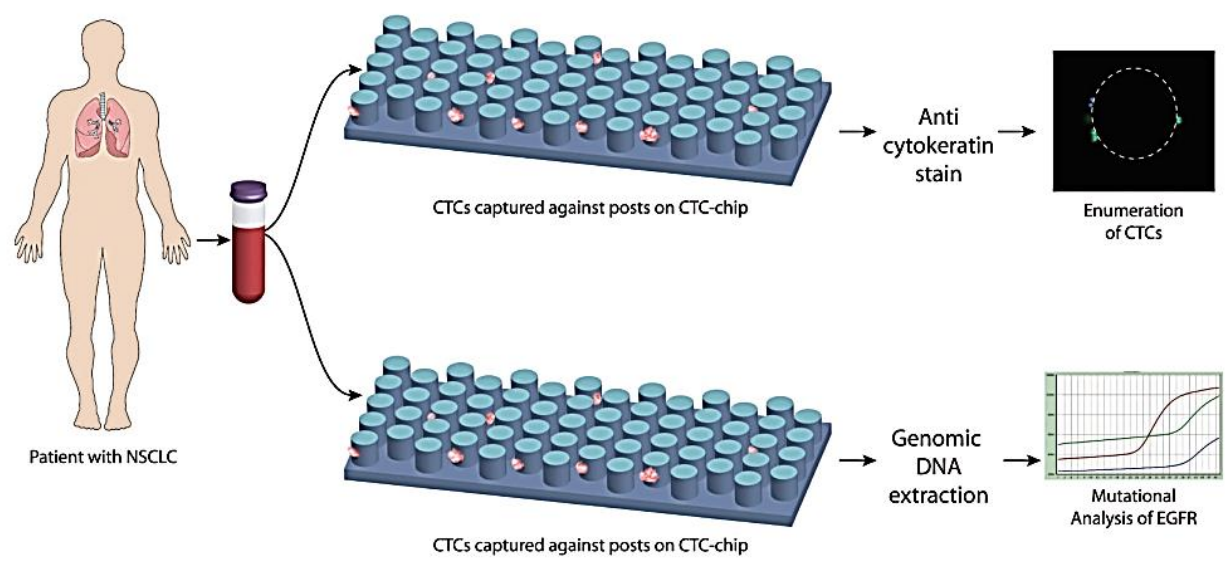

Figure 2-29: CTC-CHIP device working with DLD method and its ability for retrieving and checking on CTCs [92]

Several micro-arrays coated or functionalized with antibodies have been placed on a chip at short distances in this device [92]. Having passed on this plate, blood cells, which are smaller than the size of distances between arrays, are removed from the plate, while the CTCs are attached to the arrays containing the antibody. The next step, the CTCs captured from the chip can be counted and analyzed in various ways, including molecular characterization and DNA sequencing [132].

In the next usages of this method for the separation of the cancerous cells, it was shown that correctly inserting barriers could distinguish the path of small particles (red blood cells) from that of larger particles (cancer cells). Therefore, such a measure helps CTCs separate from the rest of the cells. Like the PFF method, this method uses the difference in the amount of Stokes number [134]. As can be seen in Figure 2-30, the fluid (blood sample) passes through several obstacles. 


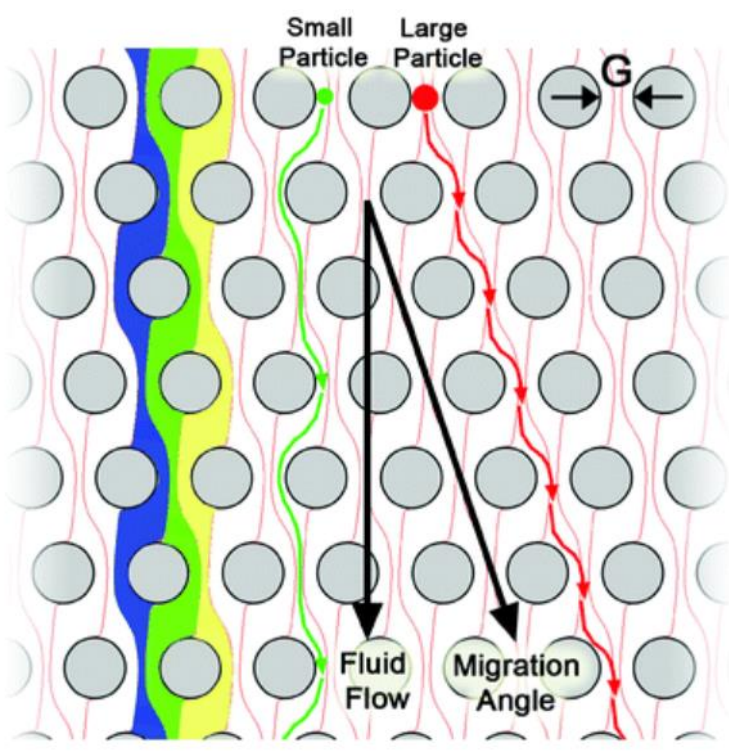

Figure 2-30: Using obstacles to direct particles

As shown in figure 2-30 for the green particle, particles with smaller Stokes number and less inertia can match their path to the fluid and pass through the obstacles. The larger and more inert particles, which are cancerous cells here, have such a high Stokes number that they cannot change their direction suddenly and collide with different obstacles. Although this method can separate particles with very high accuracy, it also has some drawbacks:

1- Due to this method's separation nature, it is impossible to separate the high flow rate containing particles because this method is only applicable in very laminar flows.

2- The input flow rate in these devices is pretty low; increasing the flow rate requires the construction of large dimension devices that reduce their performance and efficiency [32].

3- Although the inlet flow rate has been increased to $10 \mathrm{ml} / \mathrm{min}$ in the latest research on this method and the possibility of separating the living cells has been reported to be $85 \%$ [133], this method seems to be suitable only for the separation of solid, non-deformable and spherical particles. In other words, it has difficulty in biological separations, such as the separation of the deformable or non-spherical particles.

4- They have a complicated and troublesome manufacturing process due to many implemented obstacles in the path of particles and fluid [60]; because the DLD method's implementation requires the construction of obstacles with diameters of 1 micrometer, which is problematic.

5- In addition, since particles are flexible, they can cause microchannel clogging. 
6- It is impossible to perform this method on a rotational substrate (LOCD) and conventional methods of making microfluidic devices. In other words, for separation under the DLD method on a rotational platform, developing the required barriers is inherently challenging through lithography techniques, because the limitations of the current devices do not allow researchers to construct such microfluidic designs on a rotational disk.

Table 2-6: Advantages and disadvantages of separation through Deterministic Lateral Displacement method

\begin{tabular}{|c|c|}
\hline Benefits: & Limitations: \\
\hline Isolation of nucleated red blood cells (NRBCs), & $\begin{array}{c}\text { Complicated to model and fabrication space, } \\
\text { Not suitable for soft or non-spherical samples, } \\
\text { Tricky Micro-fabrication, Difficult to construct } \\
\text { barriers of } 1 \mu \mathrm{m} \text { in diameter, Low Flow rate, } \\
\text { deformable and spherical particles, } \\
\text { Inexpensive, High purity and High-throughput } \\
\text { Needs a long enough separation zone, The } \\
\text { possibility of damaging to cells }\end{array}$ \\
\hline
\end{tabular}

\section{2-3-2-5- Inertial microfluidics for continuous particle (Cancer Cell) separation in microchannels}

The particle focusing mechanism lies on the hydrodynamic inertial forces exerted on particles migrating along a microchannel, which induce particle movement away from walls and along with a distinct lateral position in the microchannel.

Inertial microfluidic systems work in relatively higher Reynolds than other microfluidics devices. Recent advances in inertial microfluidics using inertial effects such as inertial lift force and Dean flow, not using external forces and just based on size difference, lead to continuously sorting cells with high throughput. The first inertial microfluidic device was originally invented to concentrate and sort particles. Several inertial separators, using movement differences due to the cell size and its deformability for isolating CTCs, have been described in particular geometries such as straight, spiral, and multi-orifice structures. The first device was introduced in 2007 by the Di Carlo Group. In their design, having a serpentine geometric structure (Figure 2-31-1), the randomly distributed particles with an accidentally irregular arrangement in the fluid entering the device were regularly ordered along the flow direction [155]. In the next study of this group, the separation dependence on particle size and particle density in the fluid and the effect of Reynolds number have been investigated. There is also the possibility of separation for deformable particles and multi-stage separation to achieve higher purity $[118,156]$. 
Figure 1: Serpentine Structure
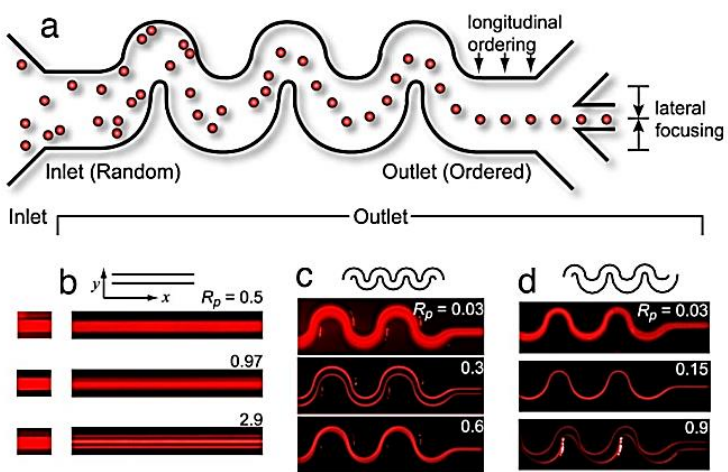

Figure 3: Multi-Stage Multi-Orifice Flow Fraction Structure
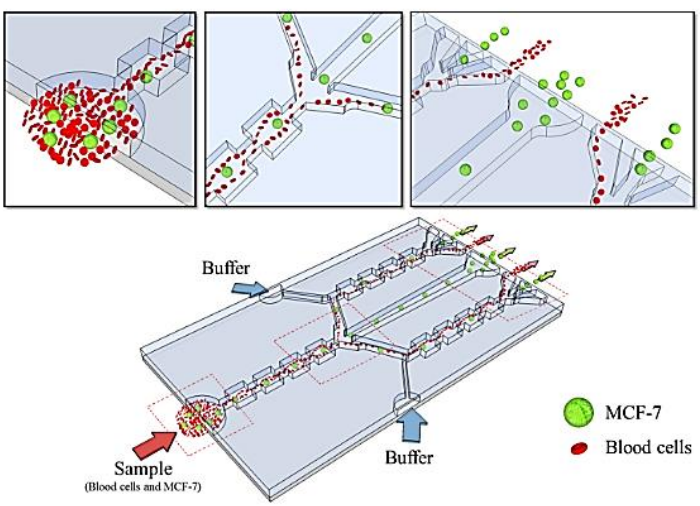

Figure 2: Spiral Structure

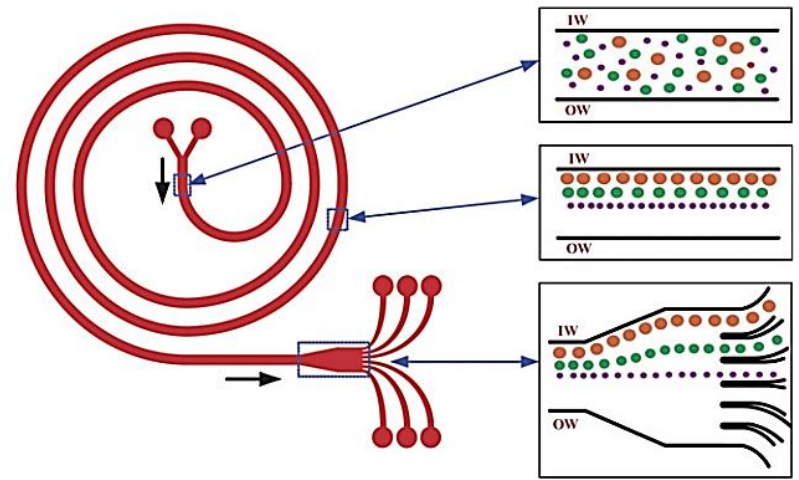

Figure 4: Continuous Contraction-Expansion Array Structure

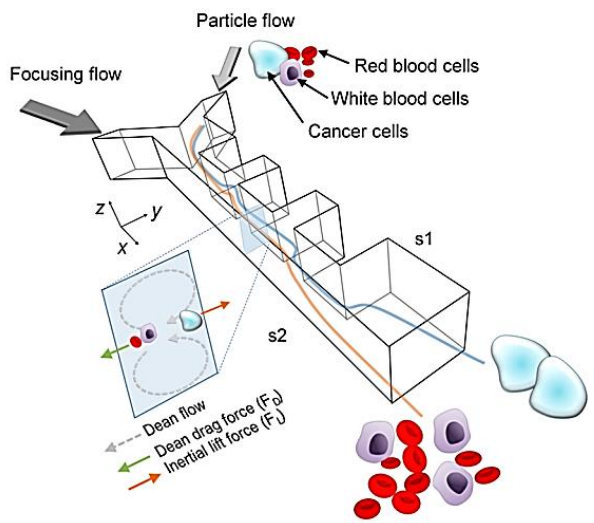

Figure 2-31: Inertial microfluidic separators 1-Serpentine structure [155] 2-Spiral structure [157] 3- Multi-Orifice flow fraction structure [158] 4- Continuous contraction-expansion array structure

After that, numerous devices with a variety of geometries have been constructed and used. One of the most popular geometries for such microfluidic devices is a spiral structure (Figure 2-31-2) [157]. These microchannels are highly regarded because of their simple geometry, precise control, microchannel length reduction, and high efficiency.

The separation level and flow rate in these channels are also high due to relatively large dimensions and the absence of obstacles; moreover, the possibility of clogging and blocking in such channels decreases. Another advantage of this design is using other diagnostic tests such as antibody indicators in the device to enhance its accuracy $[157,160]$. A couple of spiral channels have been recently combined to increase the inlet flow rate and improve the separation speed [161]. 
In this method, the fluid enters a spiral microchannel and exits through different outlets of its inner and outer walls. Larger and smaller particles accumulate near the inner and outer walls, respectively. Therefore they can separately exit and can be collected. Since the CTCs with an average diameter of $20 \mu \mathrm{m}$ have a significant size difference from the red blood cells with an approximate diameter of 8 $\mu \mathrm{m}$. Therefore, due to its precise control, simple structure, and high efficiency, the above method is appropriately enough for separating the cancer cells from the red blood cells. Bhagat and his colleagues in 2008 first presented the scheme [162]. Then, numerous attempts were accomplished to increase the efficiency of this method.

In 2012, Bhagat and his colleagues $[160,162,163]$ illustrated that changing the microchannel crosssection from rectangular to trapezoidal would dramatically boost the device efficiency and decreases the possibility of clogging and blocking in the channel. In this microchannel, as seen in figure 2-32, the fluid passes through two different spiral microchannels.
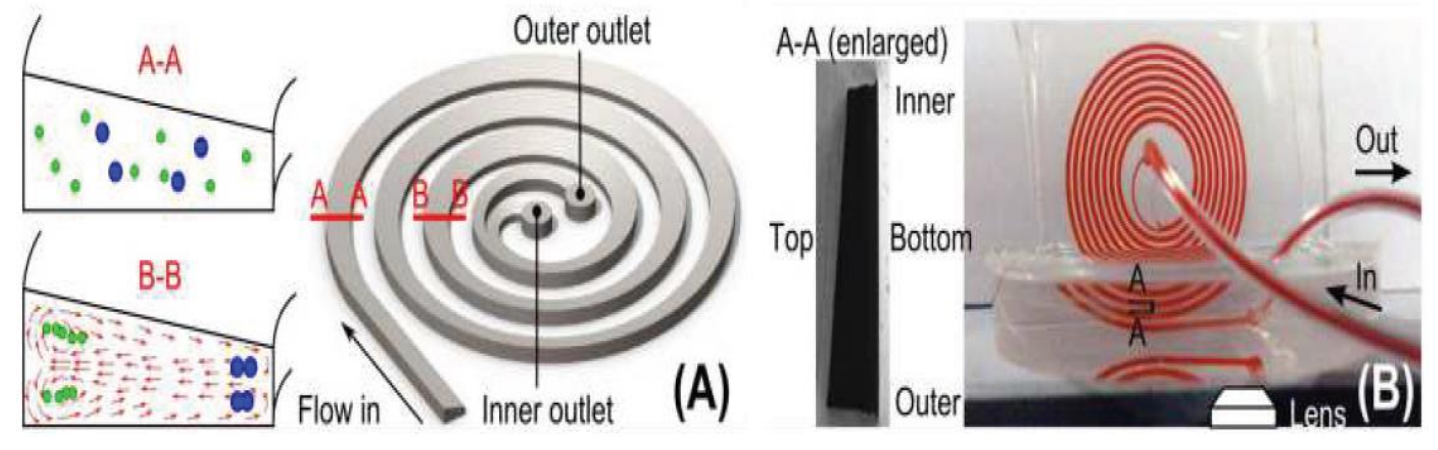

Figure 2-32: Spiral microchannel

This method can reduce the total microchannel length as a result of which the separation rate increases. Other innovations submitted to accelerate this device's separation rate include a doublelayer microchannel fabrication by Jiaoshu Sun [164]. Flat channels with sudden cross-section changes are other significant types of inertial microfluidics because of the abruptly continuous expansion and contraction in the path. A sudden change in the cross-section causes flow deviation (a similar effect of the curvature in the channel) and forms the turbulent secondary flows (Dean vortices). Expansion and contraction arrays in such systems can be designed symmetrically [66, 158, 165] (similar to combining consecutive multi-orifices flow fractionation) (Figure 2-31-3) or asymmetrically [159] (expansion and contraction at one side of the channel) (Figure 2-31-4). Asymmetric structures had been used as a mixer, concentrator of particles $[166,167]$, and as a blood cell section separator from plasma $[168,169]$ before their application for isolating the particles $[159$, 170]. As previously referred, available different methods apply various mechanisms and geometries 
for particle separating and sorting. Compared to the other sorting ones, this hydrodynamic focusing method takes some advantages of proficiency, fabrication, and operation, some of which are listed below.

First, this method profits from the high-throughput and continuous processing of the sample. Second, the microfluidic structure requires neither barrier installation nor even mechanical and electrical components. Third, the two-dimensional microfluidic channel can be fabricated through PDMS softlithography quickly and easily. Fourth, the microfluidic system can be functioned by only one syringe pump without the sheath flow usage. On the other hand, the hydrodynamic focusing method has a few weaknesses associated with sample properties and operation. First, particles inside the sample should be like rigid spheres to achieve the maximum amount of the inertial lift force. Second, particles' concentration should be sufficiently low to reach the adequate inter-particular distance because the high concentration of particles frustrates the hydrodynamic focusing. Finally, the flow rate should be maintained within an assigned range to achieve a suitable focus [165]. Therefore, this particle-focusing mechanism employing the hydrodynamic inertial forces demands many studies in the particle separation field. Microscale size-discrimination, high purity, proper recovery, working with deformable particles, and so on are some instances [165]. Another problem related to the inertial microfluidic system that has led us to this direction is the lack of ability to control flow precisely. Two proposed plans to solve this matter are clarified below.

\section{A) Use self-controlled valves to handle the fluid flow; this subject has not been investigated so far in inertial microfluidic devices for separation purposes:}

Microvalves enable the user to control fluid flow in a channel via switching the defined parameter. They can be operated by enforcing an external force, or by changing phase and so on. For example, Pneumatic microvalves (normally-open and closed membrane microvalves) perform through deflecting a flexible membrane.

Although Rasouli from the University of Saskatchewan [171] has proposed a soft self-controller (normally-closed membrane microvalve) with embedded instructions through Mosadegh's design improvement [172, 173], his investigation was solely restricted to examine the membrane deformation with different thicknesses and flow velocities of the fluid. Hence, the valve itself efficiency has not been argued in connection with the other microfluidic equipment. Furthermore, the problem of leakage observed in other's work was not thoroughly addressed during his research. 
He also did not indicate how to tackle the stickiness problem between the glass and the channel bottom, so the clearance for the fluid to flow became very difficult. However, a self-controller (not by applying an external field) to control the fluid flow is still demanded because the stable platform separators lack a flow control system. In contrast, the centrifugal microfluidics does not require any external equipment to regulate the fluid flow.

\section{B) Implementing inertial microfluidics on a rotational platform which is called Lab-on-a-CD (LOCD) to manage and control the fluid flow inside the microchannel by centrifugal forces:}

Lab-On-a-CD (LOCD) is a particular type of Lab-On-a-chip (LOC). These systems are minimal, portable, inexpensive, and disposable, which are suitable for medical fields. In these systems, the microfluidic components are established on a rotating disk platform or CD. Therefore, the generated forces in a rotational platform (i.e., centrifugal forces) can be used as flow actuators inside microchannels; consequently, the system will no longer require any external accessories as a pump. Comparatively, the rotary devices controlling fluid flow have more inherent benefits than conventional LOC and microfluidic devices that employ micro-pumps to drive fluid. Some of the advantages of this design include:

1- Centrifugal forces link directly to the drive system rotational frequency, so changing the drive engine angular velocity can regulate these forces.

2- A much more extensive range of the required force for driving or stopping fluid can be chosen in such a system by varying the angular velocity.

3- Centrifugal forces can be enlarged enough to fully overcome other forces, such as surface tension and capillary forces, and cause the fluid flow to stop.

4- Centrifugal forces can be reduced to a point where other forces override it and prompt the fluid flow to stop by only using channel geometry.

5- Centrifugal force is the independence of parameters such as viscosity, conductivity, $\mathrm{PH}$, and surface tension. These systems are substantially able to create and conduct the fluid flows with different physical properties, biological liquids, and laboratory reagents.

It should be recalled that all the above discussed inertial microfluidic types have been settled on stable substrates, while these systems can be executed on rotational platforms as well. For example, Aguirre et al. in 1998 were able to apply the zigzag spiral geometry to the centrifugal microfluidic 
system, both as a mixer and as a separator [174]. The overall purpose of this design was to detach the breast cancer cells from other blood cells; hence, to increase the target cell volume and achieve higher efficiency, the input sample was combined with particular sticky microparticles during the mixer unit before separating (Figure 2-33).

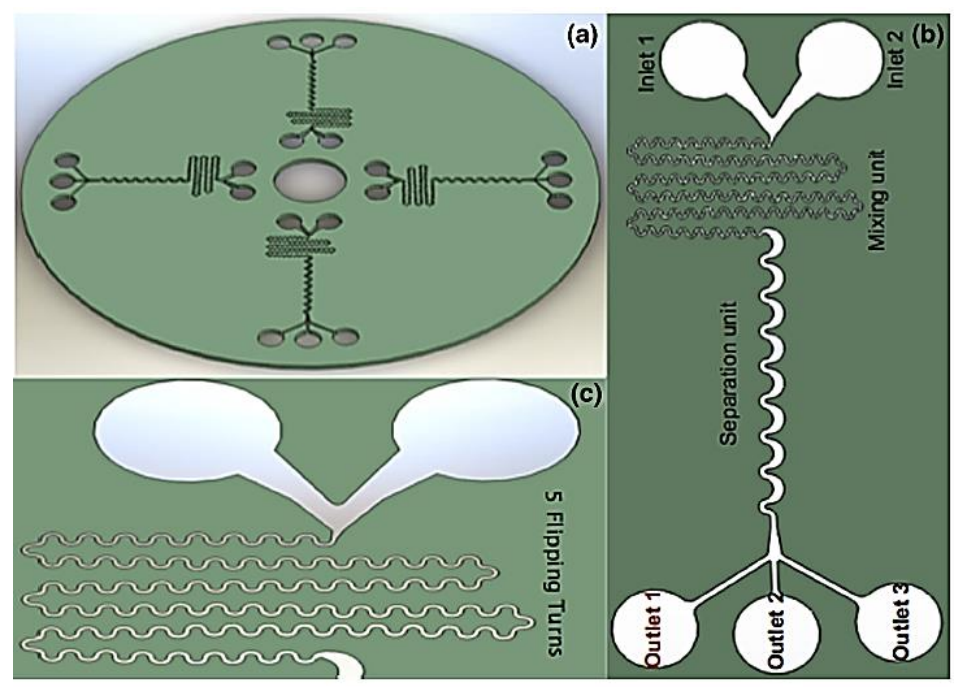

Figure 2-33: Sketch of the centrifugal microfluidic system with the inertial mixer and separator units [174]

In addition to all the positive aspects of centrifugal microfluidic systems elaborated in the previous section, these devices have some drawbacks. The most undesirable disadvantage is the difficulty of employing this method to separate CTCs from the patient's blood sample directly due to the low and limited sample volume. Consequently, another separator system as an initial step is sometimes required to concentrate the target cells; after that, during a time-consuming and sensitive process that probably causes the sample to contaminate, the concentrated sample is transferred to the centrifugal device.

Although using an initial-fixed-substrate separator at the outside of the device has been suggested to eliminate this problem and concentrate the target cells, transferring the sample from the first to the second separator is time-consuming and sensitive and makes it probably contaminated. Contrastingly, suppose the system is implemented on a rotational platform. In that case, there is a possibility that even after separating, the isolated CTCs return and enter the bloodstream again, so something like a check-valve is required to avoid this happen. Therefore, a self-controller that can control the CTCs movement and block their path is needed to be devised and performed if isolated particles are going to return to the sample after separation. 
Table 2-7: Advantages and disadvantages of separation by Inertial microfluidic separators

\begin{tabular}{|c|c|}
\hline Benefits: & Limitations: \\
\hline $\begin{array}{c}\text { Continuous and high-throughput performance, } \\
\text { High cell viability and Label-Free, Simple chip, } \\
\text { simple operation and Inexpensive, No } \\
\text { requirement about the properties of cells or } \\
\text { fluid, Reliable and fast for control, Suitable for } \\
\text { large-scale integration, Simultaneous isolation } \\
\text { of more than two types of cells, Required small } \\
\text { amounts of reagents, Separation of rare cell } \\
\text { populations }\end{array}$ & $\begin{array}{c}\text { The possibility of clogging, No ability to } \\
\text { precisely control the operation, }\end{array}$ \\
\hline
\end{tabular}




\section{3- CONCLUSION}

Separation of cells is performed based on biochemical or physical properties, each of which has its advantages and disadvantages. The separation unit can be designed passively, while external forces such as magnetic, electrical, pneumatic, and so on can be used when internal forces alone cannot meet the system expectations. Physical separation methods based on size have recently been considered owing to the low cost and simplicity in construction; for example, the two-dimensional microfluidic channel can be easily and rapidly fabricated by PDMS soft-lithography. Moreover, they enjoy relatively high separation speed and have more potential for future work and innovations. Among the various types of size-based separation methods, inertial microfluidic techniques provide the proper characteristics for a separation system due to the simple structure of the system, its simple experimental setup, the relatively large dimensions, and the ability to work with a much higher operational flow rate compared to those of other separators. In other words, this type of separation takes advantage of the high-throughput filtration of blood cells as it can accommodate a high flow rate so that it plays a significant role in precise post-processing to enhance the separation efficiency. This system's main advantages are the rapid continuous processing of samples and the absence of small filters or mechanical or electrical parts. So it would be clinically useful for preparative filtration of large volumes of blood or emulsions in a compact format. Additionally, the system operates with both rigid and deformable particles and can enrich or deplete platelets from diluted whole blood. On the other hand, weaknesses include the need to maintain flow within a range of values to achieve successful separation. Although such rapid operational separation systems are useful to increase purity and yield, some disadvantages, including pump requirement to drive the fluid, low control on cell movement, the possibility of clogging, and no ability to precisely control the operation, make the researchers think about using a rotational platform. However, only building a rotational inertial separator cannot be significantly helpful because centrifugal force is independent of cells' characteristics and cannot distinguish CTCs among other cells. In other words, centrifugal force acts on all cells, not only on CTCs; therefore, it cannot separate CTCs alone; it just makes them move forward. Consequently, another force is required to find CTCs and simultaneously match the other techniques. Reviewing the published papers in the isolation field shows that exclusive cell separation by antibody binding is the most appropriate active method to achieve hybrid separator. They target the inherent cell nature and are much more precisely than those separations based on size density. Among the cell separation methods conducted by an exclusive antibody connection, CTC isolation, utilizing magnetic nanoparticles on a rotational platform is the most appropriate active approach so that it is anticipated to be more accurate than other separation methods. For achieving this purpose, 
the antibody and the magnetic nanoparticles must first be coupled together. Then they must be mixed with the cancerous cell to have deviated in the magnetic field. Mixing magnetic nanoparticles and antibodies and then cancerous cells is another challenging issue. If mixing occurred outside of the system, sample contamination would be possible because this time-consuming operation is very sensitive. The researchers suggest that all procedures proceed on a single platform leading to reduced clogging because of centrifugal force, high accuracy because of two separators, and reduced contamination. Experimental results show that implementing a separator on a rotational platform improves its efficiency and covers most weaknesses of active and passive methods. Hence, separating CTCs on a rotational inertial microfluidic device while the magnetic field is applied would be an asset to design a novel microfluidic separator boosting the separation efficiency. Nonetheless, such a measure requires a thorough comprehension of the different types of separation methods, their manufacturing process, and familiarity with their restrictions. Table 2-8 shows the cell separation devices along with their required sample size. These separators have successfully developed and reached the commercialization stage.

Table 2-8: Commercial Cell Separation Devices

\begin{tabular}{|c|c|c|c|c|}
\hline $\begin{array}{c}\text { Name of } \\
\text { Devices }\end{array}$ & Tumor Origin & Mechanism & $\begin{array}{c}\text { Required } \\
\text { sample size }\end{array}$ & $\begin{array}{c}\text { Year of } \\
\text { market } \\
\text { entry }\end{array}$ \\
\hline MACs [63] & Bone marrow & $\begin{array}{c}\text { Active, Cell-labeling, } \\
\text { Microfluidics }\end{array}$ & 1990 \\
\hline MFACs [52] & Breast & $\begin{array}{c}\text { Passive, Cell-labeling, } \\
\text { Microfluidics }\end{array}$ & $30 \mathrm{ml}$ & 1999 \\
\hline ISET [61] & Liver & $\begin{array}{c}\text { Passive, Non-Cell-labeling, } \\
\text { Non-Microfluidics }\end{array}$ & 2000 \\
\hline CTC-Chip & $\begin{array}{c}\text { Pancreas, Breast, } \\
\text { Prostate, } \\
\text { Intestine, Lung }\end{array}$ & $\begin{array}{c}\text { Passive, Cell-labeling, } \\
\text { Microfluidics }\end{array}$ & $0.9 \mathrm{ml}$ & 2007 \\
\hline $\begin{array}{c}\text { Cell Search } \\
\text { [65] }\end{array}$ & $\begin{array}{c}\text { Breast, Intestine, } \\
\text { Prostate }\end{array}$ & $\begin{array}{c}\text { Active, Cell-labeling, } \\
\text { Microfluidics }\end{array}$ & $7.5 \mu \mathrm{ml}$ & 2009 \\
\hline $\begin{array}{c}\text { EPISPOT } \\
\text { assay [175] }\end{array}$ & $\begin{array}{c}\text { Breast, Intestine, } \\
\text { Prostate, Thyroid } \\
\text { glands }\end{array}$ & $\begin{array}{c}\text { Active, Cell-labeling, Non- } \\
\text { Microfluidics }\end{array}$ & $8 \mathrm{ml}$ & 2012 \\
\hline
\end{tabular}


Acknowledgments: The authors gratefully acknowledge the Department of Mechanical at the University of Saskatchewan for providing us the research facilities. As well, the research is made possible to the first author by the Devolved Graduate Scholarship.

Funding: This research work is not supported by any funding agency.

\section{COMPLIANCE WITH ETHICAL STANDARDS}

Conflict of interest: The authors declare that they have no conflict of interest. 


\section{4- REFERENCES}

[1] P.S. Dittrich, A. Manz, Lab-on-a-chip: microfluidics in drug discovery, Nature Reviews Drug Discovery 5(3) (2006) 210-218.

[2] L.A. Torre, F. Bray, R.L. Siegel, J. Ferlay, J. Lortet-Tieulent, A. Jemal, Global cancer statistics, 2012, CA: a cancer journal for clinicians 65(2) (2015) 87-108.

[3] L.J. Kricka, Microchips, microarrays, biochips and nanochips: personal laboratories for the 21st century, Clinica Chimica Acta 307(1-2) (2001) 219-223.

[4] P. Pisani, F. Bray, D.M. Parkin, Estimates of the world-wide prevalence of cancer for 25 sites in the adult population, International Journal of Cancer 97(1) (2002) 72-81.

[5] C.D. Chin, V. Linder, S.K. Sia, Lab-on-a-chip devices for global health: Past studies and future opportunities, Lab on a Chip 7(1) (2007) 41-57.

[6] F. Bray, A. Jemal, N. Grey, J. Ferlay, D. Forman, Global cancer transitions according to the Human Development Index (2008-2030): a population-based study, The Lancet Oncology 13(8) (2012) 790801.

[7] A. Aziz, K.H. ul Hassan, FINDING PARENTS WITH DEOXYRIBONUCLEIC ACID (DNA) DATABASE, International Journal of Computer Science and Information Security 15(1) (2017) 664.

[8] A. Kumar, A review of traditional anticancer nano-medicine: triphala, The Pharma Innovation 3(7, Part B) (2014) 60.

[9] H. Fukata, C. Mori, Epigenetic alteration by the chemical substances, food and environmental factors, Reproductive medicine and biology 3(3) (2004) 115.

[10] T. Ono, Y. Uehara, K. Fujikawa, N. Kagawa, M. Yoshida, I. Hayata, T. Nohmi, T. Matsumoto, Y. Oghiso, K. Tanaka, Alteration of genome structure induced by very low dose-rate irradiation in mouse tissues, Data Science Journal (2009) 0906210143-0906210143.

[11] V. Slepkov, V. Sukhovol'skii, R. Khlebopros, Modeling the growth and morphogenesis of malignant tumors, Doklady Biochemistry and Biophysics, Springer, 2006, pp. 342-345.

[12] E. Arora, H. Verma, A. Niranajan, Review on Targeted Cancer Therapy, Journal of Critical Reviews $7(10)$ (2020) 1204-1208.

[13] M. Dwivedi, A Perspective Review on Cancer-The Deadliest Disease, International Journal of Cancer 1(1).

[14] G.P. Gupta, J. Massague, Cancer metastasis: building a framework, Cell 127(4) (2006) 679-695.

[15] T.R. Ashworth, A Case of Cancer in Which Cells Similar to Those in the Tumours Were Seen in the Blood after Death, The Medical Journal of Australia 14 (1869) 146-149.

[16] V. Plaks, C.D. Koopman, Z. Werb, Circulating Tumor Cells, Science 341(6151) (2013) 1186-1188. 
[17] M. Kozminsky, S. Nagrath, H. Liu, J. Lathia, Circulating tumor cells, cancer stem cells, and emerging microfluidic detection technologies with clinical applications, Cancer Stem Cells; Elsevier: Amsterdam, The Netherlands (2016) 367-394.

[18] S.C. Williams, Circulating tumor cells, Proceedings of the National Academy of Sciences 110(13) (2013) 4861.

[19] W.J. Allard, J. Matera, M.C. Miller, M. Repollet, M.C. Connelly, C. Rao, A.G. Tibbe, J.W. Uhr, L.W. Terstappen, Tumor cells circulate in the peripheral blood of all major carcinomas but not in healthy subjects or patients with nonmalignant diseases, Clinical cancer research 10(20) (2004) 6897-6904. [20] R.A. Ghossein, S. Bhattacharya, J. Rosai, Molecular detection of micrometastases and circulating tumor cells in solid tumors, Clinical Cancer Research 5(8) (1999) 1950-1960.

[21] W. Ganong, K. Barrett, Review of medical physiology: Appleton \& Lange Norwalk, CT, 1995.

[22] A.G. Tibbe, M.C. Miller, L.W. Terstappen, Statistical considerations for enumeration of circulating tumor cells, Cytometry Part A: the journal of the International Society for Analytical Cytology 71(3) (2007) 154-162.

[23] X. Zhe, M.L. Cher, R.D. Bonfil, Circulating tumor cells: finding the needle in the haystack, American journal of cancer research 1(6) (2011) 740-751.

[24] Y. Dong, A.M. Skelley, K.D. Merdek, K.M. Sprott, C. Jiang, W.E. Pierceall, J. Lin, M. Stocum, W.P. Carney, D.A. Smirnov, Microfluidics and circulating tumor cells, The Journal of Molecular Diagnostics 15(2) (2013) 149-157.

[25] W. Yang, A.T. Woolley, Integrated Multiprocess Microfluidic Systems for Automating Analysis, JALA: Journal of the Association for Laboratory Automation 15(3) (2010) 198-209.

[26] A. Farahinia, J. Jamaati, H. Niazmand, Study of Slip Effect on Electro-osmotic Micromixer Performance Based on Entropy Index, Amirkabir Journal of Mechanical Engineering 49(3) (2017) 535-548.

[27] A. Farahinia, J. Jamaati, H. Niazmand, Investigation of slip effects on electroosmotic mixing in heterogeneous microchannels based on entropy index, SN Applied Sciences 1(7) (2019) 728-740.

[28] A. Farahinia, J. Jamaati, H. Niazmand, W.J. Zhang, Investigation of an electro-osmotic micromixer with heterogeneous zeta-potential distribution at the wall, Engineering Research Express 1(1) (2019) 015024.

[29] J. Jamaati, A. Farahinia, H. Niazmand, Investigation of Mixing in Electroosmotic Micromixers using Nernst-Planck Equations, Modares Mechanical Engineering 15(4) (2015) 203-213. 
[30] J. Jamaati, A. Farahinia, H. Niazmand, Mixing Investigation In Combined Electroosmotic/Pressure-driven Micromixers With Heterogeneous Wall Charges Modares Mechanical Engineering 15(7) (2015) 297-306.

[31] J. Jamaati, A. Farahinia, H. Niazmand, Numerical Investigation of Electro-osmotic Flow in Heterogeneous Microchannels, Modares Mechanical Engineering 15(3) (2015) 260-270.

[32] J. Autebert, B. Coudert, F.-C. Bidard, J.-Y. Pierga, S. Descroix, L. Malaquin, J.-L. Viovy, Microfluidic: an innovative tool for efficient cell sorting, Methods 57(3) (2012) 297-307.

[33] A. Farahinia, W. Zhang, Numerical analysis of a microfluidic mixer and the effects of different cross-sections and various input angles on its mixing performance, Journal of the Brazilian Society of Mechanical Sciences and Engineering 42(4) (2020) 1-18.

[34] A. Farahinia, W.J. Zhang, Numerical investigation into the mixing performance of micro T-mixers with different patterns of obstacles, Journal of the Brazilian Society of Mechanical Sciences and Engineering 41(11) (2019) 491-504.

[35] D. Devadas, E.W. Young, Microfluidics for cell culture, Microfluidic Methods for Molecular Biology, Springer2016, pp. 323-347.

[36] F.A. Gomez, Biological applications of microfluidics, John Wiley \& Sons2008.

[37] M. Madou, J. Zoval, G. Jia, H. Kido, J. Kim, N. Kim, Lab on a CD, Annu. Rev. Biomed. Eng. 8 (2006) 601-628.

[38] D. King, M. O’Sullivan, J. Ducrée, Optical detection strategies for centrifugal microfluidic platforms, Journal of Modern Optics 61(2) (2014) 85-101.

[39] J. Steigert, M. Grumann, T. Brenner, L. Riegger, J. Harter, R. Zengerle, J. Ducrée, Fully integrated whole blood testing by real-time absorption measurement on a centrifugal platform, Lab on a Chip 6(8) (2006) 1040-1044.

[40] D.C. Duffy, H.L. Gillis, J. Lin, N.F. Sheppard, G.J. Kellogg, Microfabricated centrifugal microfluidic systems: characterization and multiple enzymatic assays, Analytical Chemistry 71(20) (1999) 46694678.

[41] I.H. Badr, R.D. Johnson, M.J. Madou, L.G. Bachas, Fluorescent ion-selective optode membranes incorporated onto a centrifugal microfluidics platform, Analytical chemistry 74(21) (2002) 55695575.

[42] G. Ekstrand, C. Holmquist, A.E. Örlefors, B. Hellman, A. Larsson, P. Andersson, Microfluidics in a Rotating CD, Springer Netherlands, Dordrecht, 2000, pp. 311-314.

[43] J. Ducrée, S. Haeberle, T. Brenner, T. Glatzel, R. Zengerle, Patterning of flow and mixing in rotating radial microchannels, Microfluidics and Nanofluidics 2(2) (2006) 97-105. 
[44] J. Ducrée, S. Haeberle, S. Lutz, S. Pausch, F. Von Stetten, R. Zengerle, The centrifugal microfluidic Bio-Disk platform, Journal of Micromechanics and Microengineering 17(7) (2007) S103.

[45] L.M. Sompayrac, How the immune system works, John Wiley \& Sons2019.

[46] N.-T. Nguyen, S.T. Wereley, S.A.M. Shaegh, Fundamentals and applications of microfluidics, Artech house2019.

[47] C.W. Shields IV, C.D. Reyes, G.P. López, Microfluidic cell sorting: a review of the advances in the separation of cells from debulking to rare cell isolation, Lab on a Chip 15(5) (2015) 1230-1249.

[48] L.A. Herzenberg, D. Parks, B. Sahaf, O. Perez, M. Roederer, L.A. Herzenberg, The history and future of the fluorescence activated cell sorter and flow cytometry: a view from Stanford, Clinical chemistry 48(10) (2002) 1819-1827.

[49] S. Das, M. Srikanth, J.A. Kessler, Cancer stem cells and glioma, Nature clinical practice Neurology $4(8)$ (2008) 427-435.

[50] R.G. Ashcroft, P.A. Lopez, Commercial high speed machines open new opportunities in high throughput flow cytometry (HTFC), Journal of immunological methods 243(1-2) (2000) 13-24.

[51] Y. Hirai, D. Takagi, S. Anai, Y. Chihara, T. Tsuchiya, K. Fujimoto, Y. Hirao, O. Tabata, ALA-induced fluorescence detection with photoresist-based microfluidic cell sorter for bladder cancer diagnosis, Sensors and Actuators B: Chemical 213 (2015) 547-557.

[52] A.Y. Fu, C. Spence, A. Scherer, F.H. Arnold, S.R. Quake, A microfabricated fluorescence-activated cell sorter, Nature biotechnology 17(11) (1999) 1109-1111.

[53] T.-H. Wu, Y. Chen, S.-Y. Park, J. Hong, T. Teslaa, J.F. Zhong, D. Di Carlo, M.A. Teitell, P.-Y. Chiou, Pulsed laser triggered high speed microfluidic fluorescence activated cell sorter, Lab on a Chip 12(7) (2012) 1378-1383.

[54] S. Technologies, The Typical RosetteSep ${ }^{\mathrm{TM}}$ Protocol.

[55] S. Mittal, A. Mielnik, A. Bolyakov, P. Schlegel, D. Paduch, Initial experience with fluorescence activated cell sorting of spermatozoa from testis tissue: a novel method for sperm isolation after TESE, Fertility and Sterility 106(3) (2016) e92.

[56] M.M. Wang, E. Tu, D.E. Raymond, J.M. Yang, H. Zhang, N. Hagen, B. Dees, E.M. Mercer, A.H. Forster, I. Kariv, Microfluidic sorting of mammalian cells by optical force switching, Nature biotechnology 23(1) (2005) 83-87.

[57] C. Chen, S. Zappe, O. Sahin, X. Zhang, M. Fish, M. Scott, O. Solgaard, Design and operation of a microfluidic sorter for Drosophila embryos, Sensors and Actuators B: Chemical 102(1) (2004) 59-66. 
[58] J. Krüger, K. Singh, A. O'Neill, C. Jackson, A. Morrison, P. O'Brien, Development of a microfluidic device for fluorescence activated cell sorting, Journal of micromechanics and microengineering 12(4) (2002) 486.

[59] B.-H. Jo, L.M. Van Lerberghe, K.M. Motsegood, D.J. Beebe, Three-dimensional micro-channel fabrication in polydimethylsiloxane (PDMS) elastomer, Journal of microelectromechanical systems 9(1) (2000) 76-81.

[60] N. Nivedita, I. Papautsky, Continuous separation of blood cells in spiral microfluidic devices, Biomicrofluidics 7(5) (2013) 054101.

[61] G. Vona, A. Sabile, M. Louha, V. Sitruk, S. Romana, K. Schütze, F. Capron, D. Franco, M. Pazzagli, M. Vekemans, Isolation by size of epithelial tumor cells: a new method for the immunomorphological and molecular characterization of circulating tumor cells, The American journal of pathology 156(1) (2000) 57-63.

[62] M. Zborowski, J.J. Chalmers, W.G. Lowrie, Magnetic cell manipulation and sorting, Microtechnology for Cell manipulation and Sorting, Springer2017, pp. 15-55.

[63] S. Miltenyi, W. Müller, W. Weichel, A. Radbruch, High gradient magnetic cell separation with MACS, Cytometry: The Journal of the International Society for Analytical Cytology 11(2) (1990) 231238.

[64] V. Martin, C. Siewert, A. Scharl, T. Harms, R. Heinze, S. Ohl, A. Radbruch, S. Miltenyi, J. Schmitz, Immunomagnetic enrichment of disseminated epithelial tumor cells from peripheral blood by MACS, Experimental hematology 26(3) (1998) 252-264.

[65] L.J. Millet, M.E. Stewart, J.V. Sweedler, R.G. Nuzzo, M.U. Gillette, Microfluidic devices for culturing primary mammalian neurons at low densities, Lab on a Chip 7(8) (2007) 987-994.

[66] H.-S. Moon, K. Kwon, S.-I. Kim, H. Han, J. Sohn, S. Lee, H.-I. Jung, Continuous separation of breast cancer cells from blood samples using multi-orifice flow fractionation (MOFF) and dielectrophoresis (DEP), Lab on a Chip 11(6) (2011) 1118-1125.

[67] M. Alshareef, N. Metrakos, E. Juarez Perez, F. Azer, F. Yang, X. Yang, G. Wang, Separation of tumor cells with dielectrophoresis-based microfluidic chip, Biomicrofluidics 7(1) (2013) 011803.

[68] F. Yang, X. Yang, H. Jiang, W.M. Butler, G. Wang, Dielectrophoretic separation of prostate cancer cells, Technology in cancer research \& treatment 12(1) (2013) 61-70.

[69] S. Shim, K. Stemke-Hale, J. Noshari, F.F. Becker, P.R. Gascoyne, Dielectrophoresis has broad applicability to marker-free isolation of tumor cells from blood by microfluidic systems, Biomicrofluidics 7(1) (2013) 011808. 
[70] V. Gupta, I. Jafferji, M. Garza, V.O. Melnikova, D.K. Hasegawa, R. Pethig, D.W. Davis, ApoStream ${ }^{\mathrm{TM}}$, a new dielectrophoretic device for antibody independent isolation and recovery of viable cancer cells from blood, Biomicrofluidics 6(2) (2012) 024133.

[71] C. Huang, H. Liu, N.H. Bander, B.J. Kirby, Enrichment of prostate cancer cells from blood cells with a hybrid dielectrophoresis and immunocapture microfluidic system, Biomedical microdevices 15(6) (2013) 941-948.

[72] P. Augustsson, C. Magnusson, M. Nordin, H. Lilja, T. Laurell, Microfluidic, label-free enrichment of prostate cancer cells in blood based on acoustophoresis, Analytical chemistry 84(18) (2012) 79547962.

[73] J. Shi, H. Huang, Z. Stratton, Y. Huang, T.J. Huang, Continuous particle separation in a microfluidic channel via standing surface acoustic waves (SSAW), Lab on a Chip 9(23) (2009) 3354-3359.

[74] D. Sugiyama, Y. Teshima, K. Yamanaka, M.P. Briones-Nagata, M. Maeki, K. Yamashita, M. Takahashi, M. Miyazaki, Simple density-based particle separation in a microfluidic chip, Analytical Methods 6(1) (2014) 308-311.

[75] D.T. Miyamoto, Y. Zheng, B.S. Wittner, R.J. Lee, H. Zhu, K.T. Broderick, R. Desai, D.B. Fox, B.W. Brannigan, J. Trautwein, RNA-Seq of single prostate CTCs implicates noncanonical Wnt signaling in antiandrogen resistance, Science 349(6254) (2015) 1351-1356.

[76] P. Li, Z.S. Stratton, M. Dao, J. Ritz, T.J. Huang, Probing circulating tumor cells in microfluidics, Lab on a Chip 13(4) (2013) 602-609.

[77] A.H. Ng, K. Choi, R.P. Luoma, J.M. Robinson, A.R. Wheeler, Digital microfluidic magnetic separation for particle-based immunoassays, Analytical chemistry 84(20) (2012) 8805-8812.

[78] R. Zhou, C. Wang, Microfluidic separation of magnetic particles with soft magnetic microstructures, Microfluidics and Nanofluidics 20(3) (2016) 48.

[79] E.D. Pratt, C. Huang, B.G. Hawkins, J.P. Gleghorn, B.J. Kirby, Rare cell capture in microfluidic devices, Chemical engineering science 66(7) (2011) 1508-1522.

[80] H.A. Pohl, Dielectrophoresis: The behavior of neutral matter in nonuniform electric fields (Cambridge Monographs on physics), Cambridge/New York: Cambridge University Press1978.

[81] T.B. Jones, T.B. Jones, Electromechanics of particles, Cambridge University Press2005.

[82] H. Chang, L. Yeo, Electrokinetically driven microfluidics and nanofluidics, Cambridge University Press2010.

[83] P.R. Gascoyne, J. Noshari, T.J. Anderson, F.F. Becker, Isolation of rare cells from cell mixtures by dielectrophoresis, Electrophoresis 30(8) (2009) 1388-1398. 
[84] I. Doh, Y.-H. Cho, A continuous cell separation chip using hydrodynamic dielectrophoresis (DEP) process, Sensors and Actuators A: Physical 121(1) (2005) 59-65.

[85] C. Qian, H. Huang, L. Chen, X. Li, Z. Ge, T. Chen, Z. Yang, L. Sun, Dielectrophoresis for bioparticle manipulation, International journal of molecular sciences 15(10) (2014) 18281-18309.

[86] J. Cheng, E.L. Sheldon, L. Wu, A. Uribe, L.O. Gerrue, J. Carrino, M.J. Heller, J.P. O'Connell, Preparation and hybridization analysis of DNA/RNA from E. coli on microfabricated bioelectronic chips, Nature biotechnology 16(6) (1998) 541-546.

[87] F.F. Becker, X.-B. Wang, Y. Huang, R. Pethig, J. Vykoukal, P. Gascoyne, Separation of human breast cancer cells from blood by differential dielectric affinity, Proceedings of the National Academy of Sciences 92(3) (1995) 860-864.

[88] A. Alazzam, B. Mathew, F. Alhammadi, Novel microfluidic device for the continuous separation of cancer cells using dielectrophoresis, Journal of separation science 40(5) (2017) 1193-1200.

[89] A.A.S. Bhagat, H. Bow, H.W. Hou, S.J. Tan, J. Han, C.T. Lim, Microfluidics for cell separation, Medical \& biological engineering \& computing 48(10) (2010) 999-1014.

[90] D. Lee, B. Hwang, Y. Choi, B. Kim, A novel dielectrophoresis activated cell sorter (DACS) to evaluate the apoptotic rate of K562 cells treated with arsenic trioxide (As203), Sensors and Actuators A: Physical 242 (2016) 1-8.

[91] D. Davis, ApoCell technology, 2017.

[92] D.A. Lavan, T. McGuire, R. Langer, Small-scale systems for in vivo drug delivery, Nature biotechnology 21(10) (2003) 1184-1191.

[93] J. Santini, John T, A.C. Richards, R. Scheidt, M.J. Cima, R. Langer, Microchips as controlled drugdelivery devices, Angewandte Chemie International Edition 39(14) (2000) 2396-2407.

[94] E. Toorisaka, K. Watanabe, H. Ono, M. Hirata, N. Kamiya, M. Goto, Intestinal patches with an immobilized solid-in-oil formulation for oral protein delivery, Acta Biomaterialia 8(2) (2012) 653658.

[95] A. Nilsson, F. Petersson, H. Jönsson, T. Laurell, Acoustic control of suspended particles in micro fluidic chips, Lab on a Chip 4(2) (2004) 131-135.

[96] F. Petersson, A. Nilsson, C. Holm, H. Jönsson, T. Laurell, Continuous separation of lipid particles from erythrocytes by means of laminar flow and acoustic standing wave forces, Lab on a Chip 5(1) (2005) 20-22.

[97] M.C. Zalis, J.F. Reyes, P. Augustsson, S. Holmqvist, L. Roybon, T. Laurell, T. Deierborg, Label-free concentration of viable neurons, hESCs and cancer cells by means of acoustophoresis, Integrative Biology 8(3) (2016) 332-340. 
[98] F. Petersson, L. Åberg, A.-M. Swärd-Nilsson, T. Laurell, Free flow acoustophoresis: microfluidicbased mode of particle and cell separation, Analytical chemistry 79(14) (2007) 5117-5123.

[99] M. Evander, L. Johansson, T. Lilliehorn, J. Piskur, M. Lindvall, S. Johansson, M. Almqvist, T. Laurell, J. Nilsson, Noninvasive acoustic cell trapping in a microfluidic perfusion system for online bioassays, Analytical chemistry 79(7) (2007) 2984-2991.

[100] L. Johansson, F. Nikolajeff, S. Johansson, S. Thorslund, On-chip fluorescence-activated cell sorting by an integrated miniaturized ultrasonic transducer, Analytical chemistry 81(13) (2009) 5188-5196.

[101] J.V. Norris, M. Evander, K.M. Horsman-Hall, J. Nilsson, T. Laurell, J.P. Landers, Acoustic differential extraction for forensic analysis of sexual assault evidence, Analytical chemistry 81(15) (2009) 6089-6095.

[102] T. Laurell, F. Petersson, A. Nilsson, Chip integrated strategies for acoustic separation and manipulation of cells and particles, Chemical Society Reviews 36(3) (2007) 492-506.

[103] X. Ding, Z. Peng, S.-C.S. Lin, M. Geri, S. Li, P. Li, Y. Chen, M. Dao, S. Suresh, T.J. Huang, Cell separation using tilted-angle standing surface acoustic waves, Proceedings of the National Academy of Sciences 111(36) (2014) 12992-12997.

[104] P. Augustsson, C. Magnusson, H. Lilja, T. Laurell, Acoustophoresis in tumor cell enrichment, Circulating Tumor Cells (2016) 227-248.

[105] P. Li, Z. Mao, Z. Peng, L. Zhou, Y. Chen, P.-H. Huang, C.I. Truica, J.J. Drabick, W.S. El-Deiry, M. Dao, Acoustic separation of circulating tumor cells, Proceedings of the National Academy of Sciences $112(16)$ (2015) 4970-4975.

[106] J.H. Kang, S. Krause, H. Tobin, A. Mammoto, M. Kanapathipillai, D.E. Ingber, A combined micromagnetic-microfluidic device for rapid capture and culture of rare circulating tumor cells, Lab on a Chip 12(12) (2012) 2175-2181.

[107] Y. Jo, F. Shen, Y.K. Hahn, J.-H. Park, J.-K. Park, Magnetophoretic sorting of single cell-containing microdroplets, Micromachines 7(4) (2016) 56.

[108] A. Thiel, A. Scheffold, A. Radbruch, Immunomagnetic cell sorting-pushing the limits, Immunotechnology 4(2) (1998) 89-96.

[109] M. Berger, J. Castelino, R. Huang, M. Shah, R.H. Austin, Design of a microfabricated magnetic cell separator, Electrophoresis 22(18) (2001) 3883-3892.

[110] K.-H. Han, A.B. Frazier, Paramagnetic capture mode magnetophoretic microseparator for high efficiency blood cell separations, Lab on a Chip 6(2) (2006) 265-273. 
[111] J. Siegrist, R. Burger, D. Kirby, L. Zavattoni, G. Kijanka, J. Ducrée, Stress-free centrifugomagnetic 2D-separation of cancer cells in a stopped-flow mode, 15th International Conference on Miniaturized Systems for Chemistry and Life Sciences (uTAS). Seattle, USA, 2011, pp. 2-6.

[112] D. Kirby, J. Siegrist, G. Kijanka, L. Zavattoni, O. Sheils, J. O’Leary, R. Burger, J. Ducrée, Centrifugomagnetophoretic particle separation, Microfluidics and nanofluidics 13(6) (2012) 899-908.

[113] D. Kirby, M. Glynn, G. Kijanka, J. Ducrée, Rapid and cost-efficient enumeration of rare cancer cells from whole blood by low-loss centrifugo-magnetophoretic purification under stopped-flow conditions, Cytometry Part A 87(1) (2015) 74-80.

[114] M. Glynn, D. Kirby, D. Chung, D.J. Kinahan, G. Kijanka, J. Ducrée, Centrifugo-magnetophoretic purification of CD4+ cells from whole blood toward future HIV/AIDS point-of-care applications, Journal of laboratory automation 19(3) (2014) 285-296.

[115] Y. Yoon, S. Kim, J. Lee, J. Choi, R.-K. Kim, S.-J. Lee, O. Sul, S.-B. Lee, Clogging-free microfluidics for continuous size-based separation of microparticles, Scientific reports 6(1) (2016) 1-8.

[116] C. Liu, C. Xue, X. Chen, L. Shan, Y. Tian, G. Hu, Size-based separation of particles and cells utilizing viscoelastic effects in straight microchannels, Analytical chemistry 87(12) (2015) 6041-6048.

[117] D. Holmes, G. Whyte, J. Bailey, N. Vergara-Irigaray, A. Ekpenyong, J. Guck, T. Duke, Separation of blood cells with differing deformability using deterministic lateral displacement, Interface focus 4(6) (2014) 20140011.

[118] D. Di Carlo, J.F. Edd, D. Irimia, R.G. Tompkins, M. Toner, Equilibrium separation and filtration of particles using differential inertial focusing, Analytical chemistry 80(6) (2008) 2204-2211.

[119] M. Yamada, M. Nakashima, M. Seki, Pinched flow fractionation: continuous size separation of particles utilizing a laminar flow profile in a pinched microchannel, Analytical chemistry 76(18) (2004) 5465-5471.

[120] A. Jain, J.D. Posner, Particle dispersion and separation resolution of pinched flow fractionation, Analytical chemistry 80(5) (2008) 1641-1648.

[121] C. Cupelli, T. Borchardt, T. Steiner, N. Paust, R. Zengerle, M. Santer, Leukocyte enrichment based on a modified pinched flow fractionation approach, Microfluidics and nanofluidics 14(3-4) (2013) 551-563.

[122] J.-S. Park, H.-I. Jung, Multiorifice flow fractionation: continuous size-based separation of microspheres using a series of contraction/expansion microchannels, Analytical chemistry 81(20) (2009) 8280-8288.

[123] P. Sajeesh, A.K. Sen, Particle separation and sorting in microfluidic devices: a review, Microfluidics and nanofluidics 17(1) (2014) 1-52. 
[124] J. Takagi, M. Yamada, M. Yasuda, M. Seki, Continuous particle separation in a microchannel having asymmetrically arranged multiple branches, Lab on a Chip 5(7) (2005) 778-784.

[125] T. Morijiri, S. Sunahiro, M. Senaha, M. Yamada, M. Seki, Sedimentation pinched-flow fractionation for size-and density-based particle sorting in microchannels, Microfluidics and nanofluidics 11(1) (2011) 105-110.

[126] R. Aoki, M. Yamada, M. Yasuda, M. Seki, In-channel focusing of flowing microparticles utilizing hydrodynamic filtration, Microfluidics and nanofluidics 6(4) (2009) 571.

[127] A. Karimi, S. Yazai, A. Ardekani, Review of cell and particle trapping in microfluidic systems, Biomicrofluidics 7 (2013) 021501.

[128] Y.-Y. Chiu, C.-K. Huang, Y.-W. Lu, Enhancement of microfluidic particle separation using crossflow filters with hydrodynamic focusing, Biomicrofluidics 10(1) (2016) 011906.

[129] L.R. Huang, E.C. Cox, R.H. Austin, J.C. Sturm, Continuous particle separation through deterministic lateral displacement, Science 304(5673) (2004) 987-990.

[130] R. Huang, T. Barber, M. Schmidt, R. Tompkins, M. Toner, D. Bianchi, R. Kapur, W. Flejter, A microfluidics approach for the isolation of nucleated red blood cells (NRBCs) from the peripheral blood of pregnant women, Prenatal Diagnosis: Published in Affiliation With the International Society for Prenatal Diagnosis 28(10) (2008) 892-899.

[131] J.A. Davis, D.W. Inglis, K.J. Morton, D.A. Lawrence, L.R. Huang, S.Y. Chou, J.C. Sturm, R.H. Austin, Deterministic hydrodynamics: taking blood apart, Proceedings of the National Academy of Sciences 103(40) (2006) 14779-14784.

[132] L.V. Sequist, S. Nagrath, M. Toner, D.A. Haber, T.J. Lynch, The CTC-chip: an exciting new tool to detect circulating tumor cells in lung cancer patients, Journal of Thoracic Oncology 4(3) (2009) 281283.

[133] K. Loutherback, J. D'Silva, L. Liu, A. Wu, R.H. Austin, J.C. Sturm, Deterministic separation of cancer cells from blood at $10 \mathrm{~mL} / \mathrm{min}$, AIP advances 2(4) (2012) 042107.

[134] C. Jin, S.M. McFaul, S.P. Duffy, X. Deng, P. Tavassoli, P.C. Black, H. Ma, Technologies for label-free separation of circulating tumor cells: from historical foundations to recent developments, Lab on a Chip 14(1) (2014) 32-44.

[135] J. Beech, Microfluidics separation and analysis of biological particles, Lund University2011.

[136] H.M. Ji, V. Samper, Y. Chen, C.K. Heng, T.M. Lim, L. Yobas, Silicon-based microfilters for whole blood cell separation, Biomedical microdevices 10(2) (2008) 251-257.

[137] T.A. Crowley, V. Pizziconi, Isolation of plasma from whole blood using planar microfilters for lab-on-a-chip applications, Lab on a Chip 5(9) (2005) 922-929. 
[138] V. VanDelinder, A. Groisman, Separation of plasma from whole human blood in a continuous cross-flow in a molded microfluidic device, Analytical chemistry 78(11) (2006) 3765-3771.

[139] B.K. Lin, S.M. McFaul, C. Jin, P.C. Black, H. Ma, Highly selective biomechanical separation of cancer cells from leukocytes using microfluidic ratchets and hydrodynamic concentrator, Biomicrofluidics 7(3) (2013) 034114.

[140] Y.-C. Fung, Stochastic flow in capillary blood vessels, Microvascular research 5(1) (1973) 3448.

[141] R. Yen, Y. Fung, Effect of velocity distribution on red cell distribution in capillary blood vessels, American Journal of Physiology-Heart and Circulatory Physiology 235(2) (1978) H251-H257.

[142] G.W. Schmid-Schönbein, S. Usami, R. Skalak, S. Chien, The interaction of leukocytes and erythrocytes in capillary and postcapillary vessels, Microvascular research 19(1) (1980) 45-70.

[143] H. Jang, M.R. Haq, J. Ju, Y. Kim, S.-m. Kim, J. Lim, Fabrication of all glass bifurcation microfluidic chip for blood plasma separation, Micromachines 8(3) (2017) 67.

[144] S. Yang, A. Ündar, J.D. Zahn, A microfluidic device for continuous, real time blood plasma separation, Lab on a Chip 6(7) (2006) 871-880.

[145] U.M. Attia, S. Marson, J.R. Alcock, Design and fabrication of a three-dimensional microfluidic device for blood separation using micro-injection moulding, Proceedings of the Institution of Mechanical Engineers, Part B: Journal of Engineering Manufacture 228(6) (2014) 941-949.

[146] C.-H. Hsu, D. Di Carlo, C. Chen, D. Irimia, M. Toner, Microvortex for focusing, guiding and sorting of particles, Lab on a Chip 8(12) (2008) 2128-2134.

[147] S.L. Stott, C.-H. Hsu, D.I. Tsukrov, M. Yu, D.T. Miyamoto, B.A. Waltman, S.M. Rothenberg, A.M. Shah, M.E. Smas, G.K. Korir, Isolation of circulating tumor cells using a microvortex-generating herringbone-chip, Proceedings of the National Academy of Sciences 107(43) (2010) 18392-18397. [148] X. Yin, T. Thomas, J. Zhang, Multiple red blood cell flows through microvascular bifurcations: cell free layer, cell trajectory, and hematocrit separation, Microvascular research 89 (2013) 47-56.

[149] J. Yang, S.S. Yoo, T.-R. Lee, Effect of fractional blood flow on plasma skimming in the microvasculature, Physical Review E 95(4) (2017) 040401.

[150] N. Takeishi, Y. Imai, T. Yamaguchi, T. Ishikawa, Flow of a circulating tumor cell and red blood cells in microvessels, Physical Review E 92(6) (2015) 063011.

[151] J. Nam, J.K.S. Tan, B.L. Khoo, B. Namgung, H.L. Leo, C.T. Lim, S. Kim, Hybrid capillary-inserted microfluidic device for sheathless particle focusing and separation in viscoelastic flow, Biomicrofluidics 9(6) (2015) 064117. 
[152] J. Oakey, J. Allely, D.W. Marr, Laminar-flow-based separations at the microscale, Biotechnology progress 18(6) (2002) 1439-1442.

[153] N.A. Mortensen, Comment on" Pinched flow fractionation: Continuous size separation of particles utilizing a laminar flow profile in a pinched microchannel", arXiv preprint arXiv:0710.5840 (2007).

[154] H. Maenaka, M. Yamada, M. Yasuda, M. Seki, Continuous and size-dependent sorting of emulsion droplets using hydrodynamics in pinched microchannels, Langmuir 24(8) (2008) 4405-4410.

[155] D. Di Carlo, D. Irimia, R.G. Tompkins, M. Toner, Continuous inertial focusing, ordering, and separation of particles in microchannels, Proceedings of the National Academy of Sciences 104(48) (2007) 18892-18897.

[156] D.R. Gossett, D.D. Carlo, Particle focusing mechanisms in curving confined flows, Analytical chemistry 81(20) (2009) 8459-8465.

[157] S.S. Kuntaegowdanahalli, A.A.S. Bhagat, G. Kumar, I. Papautsky, Inertial microfluidics for continuous particle separation in spiral microchannels, Lab on a Chip 9(20) (2009) 2973-2980.

[158] H.-S. Moon, K. Kwon, K.-A. Hyun, T. Seok Sim, J. Chan Park, J.-G. Lee, H.-I. Jung, Continual collection and re-separation of circulating tumor cells from blood using multi-stage multi-orifice flow fractionation, Biomicrofluidics 7(1) (2013) 014105.

[159] M.G. Lee, J.H. Shin, C.Y. Bae, S. Choi, J.-K. Park, Label-free cancer cell separation from human whole blood using inertial microfluidics at low shear stress, Analytical chemistry 85(13) (2013) 6213-6218.

[160] H.W. Hou, M.E. Warkiani, B.L. Khoo, Z.R. Li, R.A. Soo, D.S.-W. Tan, W.-T. Lim, J. Han, A.A.S. Bhagat, C.T. Lim, Isolation and retrieval of circulating tumor cells using centrifugal forces, Scientific reports 3 (2013) 1259.

[161] M.E. Warkiani, B.L. Khoo, L. Wu, A.K.P. Tay, A.A.S. Bhagat, J. Han, C.T. Lim, Ultra-fast, label-free isolation of circulating tumor cells from blood using spiral microfluidics, Nature protocols 11(1) (2016) 134-148.

[162] A.A.S. Bhagat, S.S. Kuntaegowdanahalli, I. Papautsky, Continuous particle separation in spiral microchannels using dean flows and differential migration, Lab on a Chip 8(11) (2008) 1906-1914. [163] A.A.S. Bhagat, S.S. Kuntaegowdanahalli, I. Papautsky, Inertial microfluidics for continuous particle filtration and extraction, Microfluidics and nanofluidics 7(2) (2009) 217-226.

[164] J. Sun, M. Li, C. Liu, Y. Zhang, D. Liu, W. Liu, G. Hu, X. Jiang, Double spiral microchannel for labelfree tumor cell separation and enrichment, Lab on a chip 12(20) (2012) 3952-3960. 
[165] J.-S. Park, S.-H. Song, H.-I. Jung, Continuous focusing of microparticles using inertial lift force and vorticity via multi-orifice microfluidic channels, Lab on a Chip 9(7) (2009) 939-948.

[166] M.G. Lee, S. Choi, J.-K. Park, Rapid laminating mixer using a contraction-expansion array microchannel, Applied Physics Letters 95(5) (2009) 051902.

[167] M.G. Lee, S. Choi, J.-K. Park, Rapid multivortex mixing in an alternately formed contractionexpansion array microchannel, Biomedical microdevices 12(6) (2010) 1019-1026.

[168] M.G. Lee, S. Choi, H.-J. Kim, H.K. Lim, J.-H. Kim, N. Huh, J.-K. Park, Inertial blood plasma separation in a contraction-expansion array microchannel, Applied Physics Letters 98(25) (2011) 253702.

[169] M.G. Lee, J.H. Shin, S. Choi, J.-K. Park, Enhanced blood plasma separation by modulation of inertial lift force, Sensors and Actuators B: Chemical 190 (2014) 311-317.

[170] M.G. Lee, S. Choi, J.-K. Park, Inertial separation in a contraction-expansion array microchannel, Journal of Chromatography A 1218(27) (2011) 4138-4143.

[171] A. Rasouli, A step towards a new micro-fluidic switch valve with embedded instructions, Department of Mechanical Engineering, University of Saskatchewan, Canada, 2018, p. 91.

[172] B. Mosadegh, C.-H. Kuo, Y.-C. Tung, Y.-s. Torisawa, T. Bersano-Begey, H. Tavana, S. Takayama, Integrated elastomeric components for autonomous regulation of sequential and oscillatory flow switching in microfluidic devices, Nature physics 6(6) (2010) 433.

[173] B. Mosadegh, T. Bersano-Begey, J.Y. Park, M.A. Burns, S. Takayama, Next-generation integrated microfluidic circuits, Lab on a Chip 11(17) (2011) 2813-2818.

[174] G.R. Aguirre, V. Efremov, M. Kitsara, J. Ducrée, Integrated micromixer for incubation and separation of cancer cells on a centrifugal platform using inertial and dean forces, Microfluidics and Nanofluidics 18(3) (2015) 513-526.

[175] C. Alix-Panabières, EPISPOT assay: detection of viable DTCs/CTCs in solid tumor patients, Minimal Residual Disease and Circulating Tumor Cells in Breast Cancer, Springer2012, pp. 69-76. 